\title{
Valoración de la carga de trabajo de auxiliar en residencias para personas mayores ( $1^{\mathrm{a}}$ parte: modelo teórico)
}

\author{
Lares Euskadi
}

\author{
Alejandro Gómez Ordoki \\ <ago2804@gmail.com>
}

\author{
Fundación Aspaldiko
}

Fundación Miranda

\section{Santa y Real Casa de Misericordia de Bilbao}

\author{
Aita Menni \\ Fundación Zorroaga
}

\author{
Bertan aurkezten den ikerkuntza-proiektuak \\ xede du arreta-profil desberdinetarako geriatria \\ laguntzailearen premia, konbinatzen direlarik \\ Barthel indizea eta Mendekotasuna Baloratzeko \\ Baremoa (MBB), eta oinarritzen da Euskadi \\ eta Nafarroako zentro geriatriko batzuetako \\ esperientzietako ratio estandarizatuetako \\ eredu teoriko batean. Administrazio publikoek \\ arreta-eredua hirugarren sektorearen errealitate \\ aldakorraren arabera egokitu arren, gure ustez, \\ sektorea osatzen dugun erakundeek heldutasun \\ profesional nahikoa lortu dugu gure ezaguera \\ praktikoan oinarritutako diseinu desberdin batzuek \\ proposatzeko, eta gainera, metodologia baliagarri \\ bilakatu daitezke beste kolektibo profesional \\ batzuek ratioen kalkuluak egiteko. Foru-lurralde \\ desberdinen partaidetzaz, ekimenerako esparrua \\ definitzeaz gain, nahi dugu testuinguruan kokatu \\ geografia eta kulturalki homogeneoak diren \\ zentroetako zerbitzuen prestazioa.
}

\section{GAKO-HITZAK:}

Pertsona adinduentzako egoitza-zentroak, geriatriako laguntzaileen ratioak, hirugarren pertsona baten premia, eguneroko bizimoduko jarduerak (EBJ), geriatrikoetako zuzeneko arretazerbitzuen katalogoa, ikuskaritza.
El proyecto de investigación que aquí se presenta busca medir la necesidad de auxiliar de geriatría para los diferentes perfiles de atención, combinando el índice Barthel con el Baremo de Valoración de la Dependencia (BVD), a través de un modelo teórico de asignación de ratios estandarizadas basado en la experiencia de varios centros geriátricos de Euskadi y Navarra. Si bien las administraciones públicas han ido adaptando los modelos de atención a la realidad cambiante del tercer sector, entendemos que las organizaciones que lo conformamos hemos alcanzado la suficiente madurez profesional para proponer diseños alternativos fundados en nuestros propios conocimientos prácticos y que, además, puedan constituir una metodología válida para el cálculo de ratios en otros colectivos profesionales. Con la participación de entidades de distintos territorios forales, además de definir un marco común de actuación, perseguimos contextualizar la prestación del servicio en centros geográfica y culturalmente homogéneos.

\section{Palabras Clave:}

Centros residenciales para la tercera edad, ratios de auxiliar de geriatría, valoración de la dependencia, necesidad de ayuda de tercera persona, actividades de la vida diaria (AVD), catálogo de servicios en atención directa en geriátricos, supervisión. 


\section{Introducción}

Desde hace tiempo, los servicios residenciales para personas mayores ubicados en el País Vasco han buscado un instrumento capaz de estimar tiempos de atención directa, y en pos de ese objetivo, han trazado diferentes caminos con resultados dispares cuando, en realidad, no hay razones ni económicas ni sociales que expliquen esta dispersión. Por ello, plantear un escenario común donde tratar idénticos problemas de manera análoga y consensuada debe ser el camino para llegar a patrones de funcionamiento que garanticen la obtención de resultados homogéneos y, por tanto, comparables. Un proyecto con este objetivo, además de ser ambicioso en su ánimo, debe constituirse en el lenguaje que todos los agentes partícipes entienden y utilizan.

Al igual que en el sector paralelo de la sanidad, se empieza a reconocer que las herramientas económicas son tan importantes para la atención geriátrica como los avances técnicos (en materia de diagnosis, de ayudas mecánicas para incrementar la autonomía, de evaluación de servicios). Debemos, por un lado, mejorar en los procesos de atención y prevención, y por otro, aumentar la producción para satisfacer una demanda cada vez más amplia, diversa y compleja. Como en cualquier otro sector, el de los servicios sociales busca la producción de servicios (output) bajo el condicionante de la limitación de recursos (input) y, claro está, con el ánimo de conseguir la mejora continua propia de los procesos de calidad en clave de eficiencia. Si somos capaces de medir los niveles de necesidad de la persona usuaria con un mismo patrón, y si también estuviéramos en disposición de diseñar un proceso común para identificar la carga de trabajo de atención directa en la satisfacción de la demanda de asistencia del usuario, tendríamos resuelto gran parte del problema.

El estudio de variables como el perfil de usuario -a través del Baremo de Valoración de la Dependencia (BVD) u otros instrumentos de diferente contenido y fin (RUG, PLAISIR, MAC 11, SIS), la intensidad de ayuda de auxiliar de clínica, el tiempo de auxiliar de clínica o la eficiencia, por citar algunas, buscan que la racionalidad impregne la distribución de recursos -escasos- en este tipo de proyectos sociales. Como profesionales de los servicios sociales, pensamos que los recursos destinados al sector están perfectamente justificados; creemos, incluso, que la evolución experimentada en las tres últimas décadas demandaría un mayor volumen de medios (los datos sobre la tendencia de los trastornos cognitivos en personas mayores o la propia conciencia social así lo corroboran). No obstante, la realidad socioeconómica cuestiona esta pretendida absorción de recursos, porque también somos conocedores de la proyección económica de otros sectores (sanidad y Seguridad Social). Y por ende, sólo con una perspectiva de racionalización de recursos conseguiremos maximizar la producción de servicios de manera que se minimicen las demandas sin atender.
No descubrimos nada si afirmamos que el recurso principal en un servicio residencial para personas mayores es lo que comúnmente denominamos como auxiliar de geriatría. Un input que explica, por sí mismo, el $60 \%$ de los costes de personal, que significan, a su vez, el $75-80 \%$ de los costes totales; en otras palabras, podemos concluir que, por término medio, el coste del colectivo profesional objeto de este estudio explica, por sí sólo, aproximadamente un $50 \%$ del coste total. Por ello, considerado este peso específico y consensuado un protocolo para definir la tipología de usuario, un siguiente paso nos llevará a una de las máximas ambiciones del sector: la asignación de ratios de auxiliar en función de un determinado perfil de necesidades o, lo que es lo mismo, la identificación de isogrupos o grupos de residentes que necesitan un nivel de atención similar. La medición de esta variable dependerá del programa de actividades diarias o de los programas individualizados de atención, del case mix de la residencia, de la intensidad de la ayuda y de la definición de las actividades, muchas veces sobreentendidas y que en la mayoría de los casos no tienen coincidencia conceptual ni tampoco temporal (la experiencia lo ha demostrado en repetidas ocasiones).

\section{Objetivo y escenario actual}

El objetivo de este trabajo es la obtención de tiempos estandarizados de auxiliar en función de la tipología del residente, mediante el diseño de una herramienta que permita su cálculo. En consecuencia, antes de empezar cualquier labor de campo, tendremos que decidir qué protocolo usaremos en la definición del perfil de usuario. Posteriormente, se procederá a instruir a un número determinado de medidores, de manera que la información recogida se ajuste al rigor requerido tanto técnica como conceptualmente. Si, como cabe esperar, la evaluación $a$ priori del residente se realiza de acuerdo al BVD - o cualquier otra herramienta de carácter intuitivo, de fácil interpretación, objetiva y que no requiera un tiempo de aplicación excesivo, como por ejemplo, el índice Barthel-, este estudio no pretende buscar argumentos para discutir la validez de estos protocolos, sino más bien llegar a un patrón conceptual común de los distintos ítems que podrían contemplar. Porque, en la actualidad, no todas las residencias ven bajo un mismo prisma las diferentes actividades de la vida diaria. En todos los geriátricos vascos se sabe lo que es una actividad como ‘alimentación', pero ¿en cuántos esta actividad está igualmente definida? Para algunos, el tiempo de atención directa imputable será aquel prestado por una auxiliar en dar de comer al residente; para otros, también debería sumarse el tiempo empleado en preparar la mesa por una camarera-limpiadora; quizás haya residencias en las que la atención directa e indirecta no tienen una frontera clara, por cuanto que los servicios son prestados por religiosas o subcontratas de atención integral. Es evidente que no hay universalidad de criterios.

Por otra parte, la experiencia demuestra que los tiempos de atención fijos para una determinada 
tipología de usuario son una verdad a medias. Dos residentes con un mismo perfil pueden presentar diferentes tiempos de atención; incluso, un mismo residente, en dos momentos distintos, también puede requerir atención de diferente manera y, por tanto, con tiempos desiguales. No estamos hablando de producir output (por ejemplo, una estancia o día de atención) bajo unas determinadas condiciones que permanecen constantes en el tiempo, aunque los servicios sociales sean un proceso de producción que, como cualquier otro, convierte recursos (input) en resultados (output). Además, en esta dinámica, deben ser eficientes, capaces de maximizar la producción bajo los condicionantes marcados por la limitación de recursos (entre éstos, el personal de atención directa destaca especialmente, por cantidad de uso y precio unitario). Pero la atención a una persona mayor no se puede comparar con cualquier proceso de producción. Si bien sobre ambos influye lo que Martin Knapp (1988) ha definido como recursos tangibles, o de composición física (bienes de equipo, personal, suministros), sobre el segundo influyen variables intangibles, o que tienen que ver con aspectos sociales o psicológicos del residente y su entorno sociofamiliar (por ejemplo, el ánimo, la autonomía o el conocimiento). En otras palabras, mediante la contabilidad analítica podemos llegar a conocer el tiempo de producción de un determinado producto -siempre el mismo- con exactitud casi matemática; sin embargo, nunca llegaremos a esa precisión en la producción de servicios para la tercera edad. Estableciendo un símil, un output residencial es como analizar una empresa de producción donde cada output es normalmente distinto del anterior y, aun cuando aparentemente fueran iguales, cada uno necesita una composición diferente. Todo esto nos empuja a entrar en un mundo de aleatoriedad y azar, de dispersión, de valores esperados y correlaciones, de pruebas no paramétricas e intervalos de confianza sobre el tiempo de auxiliar de clínica necesario para una determinada tipología de usuario, conceptos pertenecientes al ámbito de la estadística

Pero en el sector vasco de las residencias de personas mayores, el diseño de un instrumento de medición de la ratio de personal directo presenta una serie de limitaciones de trabajo, que podríamos resumir en tres:

- Falta de información: el sector de atención residencial a personas mayores no cuenta con una tabla de frecuencias donde se registren los momentos del día en que es necesaria la ayuda de tercera persona (una restricción especialmente importante en la estimación de tiempos de auxiliar en módulos psicogeriátricos). Además, no todas las entidades del sector miden las necesidades del usuario conforme a idénticos indicadores o baremos, lo que dificulta más el análisis, por cuanto no disponemos de un marco homogéneo de información.

- Verosimilitud: una vez realizada la labor de campo y explotados los datos, deberán obtenerse resultados similares en cada centro. La razón no es otra que validar el modelo mediante la experiencia de instituciones que llevan varias décadas desarrollando una labor asistencial en Euskadi.

- Unicidad u homogeneidad: todas las problemáticas de atención deberán regularse de un modo común y único. El sistema resultante debe basarse en el tratamiento universal de las diferentes casuísticas y perfiles de atención.

En cualquier caso, la información estadística sobre las frecuencias de necesidad de auxiliar de geriatría no debe limitarse al estudio de la correlación entre puntuación de la escala correspondiente (BVD, Barthel, RUG) y tiempo de atención directa. La existencia de factores exógenos -o intangibles, como los denomina Knapp (1988)- obliga a realizar una labor de campo más diversificada, porque el tiempo de auxiliar también depende de la disposición del residente y del propio trabajador. Por tanto, la muestra de nuestro estudio deberá respetar todos estos condicionantes y ser capaz, además, de responder a las siguientes preguntas:

- ¿Qué hay de cierto en afirmar que tiempo y grado de discapacidad son directamente proporcionales?: nada; pese a estar generalmente admitido, no por ello es verosímil. Como empíricamente se demuestra, la relación entre ambas variables puede ser directamente proporcional o variable (directa hasta un punto de inflexión e indirecta a partir de éste, o al contrario). La repetición de observaciones en el tiempo para un mismo residente y la colección de datos para diferentes tipologías ayudarán a definir cuáles son en realidad las relaciones que se pueden establecer entre el tiempo y el perfil del usuario. Utilizando herramientas estadísticas, podremos estimar, para un nivel de confianza mínimamente aceptado, la validez de nuestras inferencias y estimaciones.

- Interactividad de la herramienta: una manera de avanzar en el convencimiento de lo que se plantea es la posibilidad de 'jugar' con los datos propios de cada centro desde un primer momento. Por ello, se instalará un modelo apriorístico de introducción y explotación de datos, para ir ajustándolo a medida que analicemos éstos. Para que el modelo sea eficaz, previamente deberemos consensuar quién mide y qué queremos medir, con qué herramienta, durante cuánto tiempo y a quiénes. En definitiva, se trata de llegar a acuerdos con la estructura de información que todos los centros comparten. En este sentido, quizás la propia dinámica del grupo de trabajo aconseje abandonar la aplicabilidad de escalas al uso y, mediante la simple observación de la realidad, poder deducir un patrón común, sencillo e intuitivo que describa todas las etapas en la atención de las actividades de la vida diaria. Incluso - ¿por qué no?-, disponer de una herramienta informática que permita simular perfiles y tiempos teóricos conforme al patrón y sujetos a revisión empírica para su validación, como otra aplicación más de la herramienta en construcción. 
- Acceso a la situación particular de cada entidad y comparativa con la grupal: como no podría ser de otra manera, se asegura de manera permanente el acceso a la propia información y a la situación de cada entidad participante respecto al conjunto de ellas. Esta información será de acceso inmediato en la medida que quien coordine el trabajo disponga de un número mínimo de datos de cada uno de los centros (reuniones de seguimiento del proyecto).

\section{Necesidades previas a la medición de tiempos: baremo y planificación}

\subsection{Asociación entre el Baremo de Valoración de la Dependencia y el índice Barthel, y definición del nivel de dependencia}

Si consultáramos en detalle toda la bibliografía acerca de escalas de valoración, observaríamos que existen medidores para casi todo. Así, en Discapacidad/dependencia: unificación de criterios de valoración y clasificación, publicado por el Imserso (Querejeta, 2004), llegan a identificarse hasta 23 escalas diferentes, lo que da una idea de la dispersión y la variabilidad existentes en esta materia. En todo caso, podría estimarse que cualquiera que fuera la escala administrada, los resultados globales alcanzados no variarían de modo significativo. Empíricamente se demuestra que, si bien los caminos trazados son diferentes en la medida que responden a diferentes objetivos, todos terminan en idéntico destino: la determinación de niveles de dependencia en función de la necesidad de ayuda, técnica o personal, para la realización de una determinada actividad.

Como ya se ha comentado, el índice Barthel es una escala de uso común en los geriátricos de la CAPV. Con frecuencia al menos anual, las personas mayores atendidas en la red residencial vasca son valoradas con la referida escala. Si fuéramos capaces de definir una pasarela estadísticamente significativa entre el Baremo de Valoración de la Dependencia (BVD, valoración estatal oficial) y Barthel, podríamos referenciar a esta escala el nivel de dependencia. Tras analizar los datos de varios centros, concluimos que la correspondencia entre ambas escalas es realmente considerable. Para llegar a este punto, se ha procedido a contrastar la información con pruebas no paramétricas (test de chi cuadrado) que han respetado las siguientes condiciones: aleatoriedad en la selección, número mínimo de 50 observaciones y diferencia temporal entre ambas valoraciones inferior a un año (esta última condición es resultado del análisis descriptivo realizado en uno de los centros sobre el tiempo medio transcurrido para que se produzca un cambio de nivel de dependencia en el índice Barthel).

Las pruebas de independencia con la variable $c^{2}$ determinan que ambas variables están claramente asociadas para un nivel de confianza del 0,001 $(99,9 \%)$ y 4 grados de libertad. Si bien, el propio Real Decreto 174/2011 ya establece los intervalos para cada nivel de dependencia, el índice Barthel clasifica dicho nivel conforme a otra escala. Este condicionante nos obliga a buscar fronteras en el índice para que la correspondencia entre ambos atributos sea un hecho. La Fundación Zorroaga, en la ponencia presentada en el XIV Congreso de la Asociación Vasca de Geriatría y Gerontología (Izaguirre y Calvo Aguirre, 2014), expone que es muy probable que puntuaciones por debajo de 80 puntos en el índice Barthel se correspondan con los niveles 2.1 y posteriores del Baremo de Valoración de la Dependencia. En consecuencia, el índice Barthel podría constituir un buen sustitutivo del BVD para clasificar la dependencia, habida cuenta de la antigüedad de muchas de las valoraciones oficiales (en muchos casos, se corresponden con el momento de solicitud de plaza y no con el de adjudicación y, menos aún, con el de atención).

Si analizamos el BVD y el Barthel en su propia composición, observamos que, de alguna manera, los ítems aplicables en un entorno residencial ya están recogidos en el Barthel. Así, el Cuadro 1 señala la correspondencia entre ambos instrumentos.

\begin{tabular}{|l|l|}
\hline \multicolumn{2}{|l|}{$\begin{array}{l}\text { Cuadro 1. Correspondencia entre las áreas del Baremo de } \\
\text { Valoración de la Dependencia y las del índice Barthel }\end{array}$} \\
\hline Baremo de Valoración de la Dependencia & Índice Barthel \\
\hline 1. Comer y beber & 1. Comer \\
\hline $\begin{array}{l}\text { 2. Higiene personal relacionada con la } \\
\text { micción y defecación }\end{array}$ & $\begin{array}{l}\text { 5. Deposiciones } \\
\text { 6. Micción } \\
\text { 7. Usar retrete }\end{array}$ \\
\hline 3. Lavarse & 2. Lavarse \\
\hline 4. Realizar otros cuidados corporales & 4. Arreglarse \\
\hline 5. Vestirse & 3. Vestirse \\
\hline 6. Mantenimiento de la salud & * \\
\hline 7. Cambiar y mantener la posición del cuerpo & 8. Trasladarse \\
\hline 8. Desplazarse dentro del hogar & $\begin{array}{l}\text { 9. Deambular } \\
\text { 10. Escalones }\end{array}$ \\
\hline 9. Desplazarse fuera del hogar & * \\
\hline 10. Realizar tareas domésticas & * \\
\hline
\end{tabular}

* Áreas del Baremo de Valoración de la Dependencia no contempladas por el índice Barthel.

Fuente: Elaboración propia a partir del índice Barthel y Real Decreto 174/2011.

Antes de medir el tiempo, deberemos definir el perfil conforme a lo que la OMS, a través de la Clasificación Internacional del Funcionamiento, de la Discapacidad y de la Salud (CIF), establece como criterios válidos para valorar la dependencia (Tabla 1).

Como se ve, el nivel de sensibilidad de la CIF es muy superior al del BVD (aunque éste no sea el eje sobre el que gira el proyecto, no debemos dejar de considerar este hecho). En cualquier caso, la herramienta que se ha de diseñar debe procurarnos tiempos fiables, que, además de medir la eficacia y la eficiencia de nuestras plantillas, permitan, llegado el caso, debatir el modelo de atención propuesto por los respectivos Gobiernos forales. 
Tabla 1. Coeficientes de ayuda de tercera persona, por instrumentos de valoración de dependencia y nivel de ésta (\%)

\begin{tabular}{|l|c|l|c|}
\hline \multicolumn{2}{|l|}{ Clasificación Internacional de Enfermedades } & \multicolumn{3}{l|}{ Baremo de Valoración de la Dependencia } \\
\hline Coeficientes de ayuda & Nivel de dependencia (\%) & Coeficientes de ayuda & Nivel de dependencia (\%) \\
\hline $\begin{array}{l}\text { No hay problema (ninguno, ausente, } \\
\text { insignificante) }\end{array}$ & $0-4$ & Supervisión & 90 \\
\hline Problema ligero (poco, escaso) & $5-24$ & Física parcial & \\
\hline Problema moderado (medio, regular) & $25-49$ & Sustitución máxima & 90 \\
\hline Problema grave (mucho, extremo) & $50-95$ & Apoyo especial & 95 \\
\hline Problema completo (total) & $96-100$ & & 100 \\
\hline
\end{tabular}

Fuente: Elaboración propia a partir del Real Decreto 174/2011 y Querejeta (2004).

\subsection{Planificación del proyecto}

El Cuadro 2 sintetiza el cronograma del proyecto.

\begin{tabular}{|c|c|c|c|c|c|c|c|c|c|c|c|}
\hline \multirow{2}{*}{ Fases } & \multirow{2}{*}{ Acciones } & \multicolumn{10}{|c|}{ Meses } \\
\hline & & 1 & 2 & 3 & 4 & 5 & 6 & 7 & 8 & 9 & 10 \\
\hline \multirow{3}{*}{$\begin{array}{l}\text { Definición de una comisión de } \\
\text { estudio con entidades afines } \\
\text { al proyecto (alianzas con } \\
\text { competidores) }\end{array}$} & Puesta en común de datos y experiencias previas & - & $\bullet$ & & & & & & & & \\
\hline & Diseño conjunto de la metodología & • & $\bullet$ & & & & & & & & \\
\hline & $\begin{array}{l}\text { Identificación y desarrollo de conceptos clave, de modo } \\
\text { que sean homogéneos en su definición }\end{array}$ & & • & & & & & & & & \\
\hline \multirow{3}{*}{ Desarrollo de la metodología } & Limitación del área de estudio & & & - & & & & & & & \\
\hline & $\begin{array}{l}\text { Identificación de conceptos clave (servicio, módulo, } \\
\text { componente y unidad) }\end{array}$ & & & - & & & & & & & \\
\hline & Definición del case mix del centro & & & • & & & & & & & \\
\hline \multirow{3}{*}{$\begin{array}{l}\text { Hipótesis de funcionamiento y } \\
\text { comprobación empírica de su } \\
\text { validez }\end{array}$} & Relación entre tiempo de auxiliar y tipología de usuario & & & & - & & & & & & \\
\hline & $\begin{array}{l}\text { Análisis de consistencia temporal de las relaciones } \\
\text { definidas }\end{array}$ & & & & - & & & & & & \\
\hline & $\begin{array}{l}\text { Identificación de posibles correlaciones laterales } \\
\text { (conocimiento real del residente por el profesional, } \\
\text { alteración conductual del residente) }\end{array}$ & & & & • & & & & & & \\
\hline \multirow{3}{*}{$\begin{array}{l}\text { Diseño de la herramienta } \\
\text { informática para la explotación de } \\
\text { los datos observados }\end{array}$} & Extracción de la muestra conforme a leyes estadísticas & & & & & - & - & - & $\bullet$ & & \\
\hline & $\begin{array}{l}\text { Diseño del registro de toma de tiempos para los } \\
\text { profesionales encargados de los conceptos a medir }\end{array}$ & & & & & $\bullet$ & - & - & - & & \\
\hline & $\begin{array}{l}\text { Diseño de una aplicación informática adaptada } \\
\text { y obtención de estadísticos (medias muestrales, } \\
\text { dispersión, pruebas de significación) }\end{array}$ & & & & & - & - & - & $\bullet$ & & \\
\hline \multirow{3}{*}{$\begin{array}{l}\text { Prueba piloto del modelo en los } \\
\text { centros participantes }\end{array}$} & $\begin{array}{l}\text { Comprobación empírica de los tiempos estimados } \\
\text { (comparativa entre teoría y realidad) }\end{array}$ & & & & & & & & - & • & \\
\hline & $\begin{array}{l}\text { Análisis comparativo entre los resultados obtenidos por } \\
\text { cada centro }\end{array}$ & & & & & & & & $\bullet$ & $\bullet$ & \\
\hline & Análisis de las desviaciones observadas & & & & & & & & $\bullet$ & $\bullet$ & \\
\hline \multirow{3}{*}{$\begin{array}{l}\text { Correcciones y diseño definitivo de } \\
\text { la metodología }\end{array}$} & $\begin{array}{l}\text { Redacción de documentos con las conclusiones } \\
\text { obtenidas }\end{array}$ & & & & & & & & & & \\
\hline & Estandarización del modelo & & & & & & & & & & $\bullet$ \\
\hline & $\begin{array}{l}\text { Presentación de los resultados alcanzados a la } \\
\text { Administración pública }\end{array}$ & & & & & & & & & & \\
\hline
\end{tabular}

Fuente: Elaboración propia. 


\section{4. Ítems del Baremo de Valoración de la Dependencia y del índice Barthel: identificación de módulos y componentes}

\subsection{Módulo y componente}

\subsubsection{Módulo}

Los recursos se ajustan a las necesidades concretas del usuario que recibe la prestación y requieren, por ello, de una definición previa de dichas necesidades. Evidentemente, éstas mismas se presentan de maneras muy diversas y difícilmente pueden ser enumeradas en su totalidad. En nuestro caso, trataremos de satisfacer todas las necesidades cotidianas del usuario, que, en principio, vamos a identificar con la idea de módulo.

En realidad, con el objeto de no excedernos en detalles -algo que quizás no resulte operativo-, más que de necesidades concretas, podríamos hablar de agrupaciones de necesidades de una misma naturaleza. Así, dentro de un mismo módulo, presumiblemente encontraremos diferentes necesidades. Basta con conocer que existe un conjunto de necesidades similares agrupadas bajo un mismo patrón. Por tanto, podremos definir módulo como cada una de las partes homogéneas en las que puede subdividirse el servicio de atención directa en un geriátrico.

Avanzar en nuestro análisis supone preguntarnos acerca de la composición de estos módulos. Ya hemos comentado la existencia de toda una batería de escalas, clasificadores y baremos que buscan, con mayor o menor dedicación, la descripción cualitativa y cuantitativa de las necesidades concretas que puedan presentar las personas mayores. De la observación de los ítems contemplados en el BVD y el Barthel, se deduce una casi total correspondencia con lo que previamente se ha definido conceptual- mente como 'módulo'. De alguna manera, podría afirmarse que los referidos ítems, agrupados o no, son asimilables a los módulos que nos ocupan. Además, la posibilidad de utilizar estas valoraciones -ya implantadas en nuestros centros- como punto de partida del análisis de las necesidades constituye, sin duda, una sinergia que difícilmente puede ser desaprovechada.

\subsubsection{Componente}

Llegados a este punto, podría pensarse que la asignación de tiempos a las diferentes necesidades podría ser inmediata; ciertamente, no lo es. Los módulos no constituyen, en sí mismos, unidades homogéneas de medición, porque están implícitamente presentes en muchas de las tareas profesionales de las gerocultoras y, en consecuencia, no son aislables para su medición. Por ello, previamente definiremos un concepto intermedio que, en adelante, definiremos como 'componente'. En otras palabras, buscamos contar con conceptos tangibles y, por ello, de posible medición. Así, en lugar de módulos, hablaremos de componentes. Como nuestro objetivo es estandarizar los procesos, los componentes que definamos para cada módulo también deberán estar estandarizados. Llamaremos, por tanto, componente a la suma de recursos de la misma naturaleza que dan respuesta a las necesidades inherentes a los módulos.

Algebraicamente expresado, podemos definir el tiempo necesario para satisfacer las necesidades de una determinada tipología de usuario como sigue:

$$
t=\sum_{i=1}^{i=n} \sum_{j=0}^{j=4} c_{i} \cdot i_{j}
$$

El tiempo de auxiliar $t$ es igual a la suma de $i$ componentes a $j$ intensidades.

\begin{tabular}{|c|c|c|c|c|c|}
\hline \multicolumn{6}{|c|}{ Tiempos directos } \\
\hline \multirow{2}{*}{ Cód. } & \multirow{2}{*}{ Ítem (BVD/Barthel) } & \multirow{2}{*}{ Descriptor } & \multirow{3}{*}{ Cód. } & \multicolumn{2}{|c|}{ Módulo/Componente } \\
\hline & & & & Concepto & Condiciones de medición \\
\hline 1 & \multicolumn{2}{|l|}{ Comer y beber / Comer } & & \multicolumn{2}{|c|}{ Alimentación } \\
\hline \multirow{6}{*}{\multicolumn{2}{|c|}{$\begin{array}{l}\text { Comer: consiste en llevar a } \\
\text { cabo las tareas y acciones } \\
\text { coordinadas relacionadas con } \\
\text { comer los alimentos servidos, } \\
\text { llevarlos a la boca y consu- } \\
\text { mirlos de manera adecuada } \\
\text { para la cultura local, cortar } \\
\text { o partir la comida en trozos, } \\
\text { abrir botellas y latas, usar } \\
\text { cubiertos, etc. } \\
\text { Beber: significa sujetar el } \\
\text { vaso, llevarlo a la boca y } \\
\text { beber de manera adecuada } \\
\text { para la cultura local, mezclar, } \\
\text { revolver y servir líquidos para } \\
\text { beber, abrir botellas y latas, } \\
\text { beber a través de una ayuda } \\
\text { instrumental. }\end{array}$}} & \multirow{6}{*}{$\begin{array}{l}\text { - Reconocer o alcanzar los } \\
\text { alimentos servidos. } \\
\text { - Cortar o partir la comida en } \\
\text { trozos. } \\
\text { - Usar cubiertos para llevar la } \\
\text { comida a la boca. } \\
\text { - Acercarse el recipiente de } \\
\text { bebida a la boca. }\end{array}$} & 1 & Desayuno & \multirow{5}{*}{$\begin{array}{l}\text { Desde que está sentado a la } \\
\text { mesa, tiempo correspondiente a la } \\
\text { colocación de babero (si procede), } \\
\text { la preparación de alimentos (cortar } \\
\text { carne, pelar fruta, abrir yogures), } \\
\text { darle de comer y beber (si procede), } \\
\text { limpiarle con la servilleta y tomar café } \\
\text { (si procede). }\end{array}$} \\
\hline & & & & Comida & \\
\hline & & & 3 & Merienda & \\
\hline & & & 4 & Cena & \\
\hline & & & 5 & Recena & \\
\hline & & & 6 & Encamado & $\begin{array}{l}\text { Tiempo añadido por transporte y } \\
\text { preparación de bandejas a residentes } \\
\text { encamados. }\end{array}$ \\
\hline
\end{tabular}




\begin{tabular}{|c|c|c|c|c|c|}
\hline \multirow{2}{*}{ Cód. } & \multirow{2}{*}{ Ítem (BVD/Barthel) } & \multirow{2}{*}{ Descriptor } & \multirow{3}{*}{ Cód. } & \multicolumn{2}{|l|}{ Módulo/Componente } \\
\hline & & & & Concepto & Condiciones de medición \\
\hline 2 & \multicolumn{2}{|c|}{$\begin{array}{l}\text { Higiene personal relacionada con la micción y defecación / } \\
\text { Deposiciones, micción, usar el retrete }\end{array}$} & & \multicolumn{2}{|l|}{ Control de esfínteres } \\
\hline \multirow{4}{*}{\multicolumn{2}{|c|}{$\begin{array}{l}\text { - Incluye indicar la necesidad, } \\
\text { elegir y acudir a un lugar } \\
\text { adecuado para orinar/ } \\
\text { defecar, manipular la ropa } \\
\text { antes y después, adoptar la } \\
\text { postura adecuada, y limpiarse } \\
\text { después. }\end{array}$}} & \multirow{4}{*}{$\begin{array}{l}\text { - Acudir a un lugar adecuado. } \\
\text { - Manipular la ropa. } \\
\text { - Adoptar o abandonar la } \\
\text { postura adecuada. } \\
\text { - Limpiarse. }\end{array}$} & 7 & WC sin grúa & \multirow{2}{*}{$\begin{array}{l}\text { Se medirá el tiempo total necesario } \\
\text { para defecar/miccionar, desde que } \\
\text { entramos en el WC hasta que salimos. } \\
\text { Este componente tiene implícitos otros } \\
\text { que integrarán el tiempo que se ha } \\
\text { de medir (vestir/desvestir, cambio de } \\
\text { pañal, lavarse). }\end{array}$} \\
\hline & & & 8 & WC con grúa & \\
\hline & & & 9 & $\begin{array}{l}\text { Cambio pañal diurno } \\
\text { encamados }\end{array}$ & \multirow{2}{*}{$\begin{array}{l}\text { Se medirá el tiempo total necesario } \\
\text { para hacer los cambios de pañal } \\
\text { programados de día (encamados) y } \\
\text { de noche. Se extraerá un patrón de } \\
\text { funcionamiento, que será aplicado, en } \\
\text { la medida que corresponda, al total de } \\
\text { incontinentes del centro. }\end{array}$} \\
\hline & & & 10 & Cambio pañal nocturno & \\
\hline 3 & \multicolumn{2}{|l|}{ Lavarse / Lavarse } & & \multicolumn{2}{|l|}{ Higiene personal } \\
\hline \multicolumn{2}{|c|}{$\begin{array}{l}\text { - Comprende lavarse y secarse } \\
\text { todo el cuerpo, o partes del } \\
\text { cuerpo, utilizando agua y } \\
\text { materiales y métodos apropia- } \\
\text { dos de lavado y secado, como } \\
\text { bañarse, ducharse, lavarse las } \\
\text { manos y los pies, la cara y el } \\
\text { pelo, y secarse con una toalla. }\end{array}$} & $\begin{array}{l}\text { - Abrir y cerrar grifos. } \\
\text { - Lavarse las manos. } \\
\text { - Acceder a la bañera, ducha } \\
\text { o similar. } \\
\text { - Lavarse la parte inferior del } \\
\text { cuerpo. } \\
\text { - Lavarse la parte superior del } \\
\text { cuerpo. }\end{array}$ & 12 & Ducha o baño & $\begin{array}{l}\text { Desde que se le sienta en el borde de } \\
\text { la cama o se le desnuda, hasta que se } \\
\text { le seca e hidrata. En este componente, } \\
\text { además, están implícitamente } \\
\text { presentes otros que no someteremos } \\
\text { a medición (vestir/desvestir, } \\
\text { desplazamiento a WC). }\end{array}$ \\
\hline 4 & \multicolumn{2}{|c|}{ Otros cuidados corporales / Arreglarse } & & \multicolumn{2}{|l|}{ Acicalamiento } \\
\hline \multirow{2}{*}{\multicolumn{2}{|c|}{$\begin{array}{l}\text { - Acciones y tareas que requie- } \\
\text { ren un nivel de cuidado mayor } \\
\text { que el mero hecho de lavarse } \\
\text { y secarse. }\end{array}$}} & \multirow{3}{*}{$\begin{array}{l}\text { - Peinarse. } \\
\text { - Cortarse las uñas. } \\
\text { - Lavarse el pelo. } \\
\text { - Lavarse los dientes. }\end{array}$} & 13 & Acicalamiento & $\begin{array}{l}\text { Tiempo empleado para dejar } \\
\text { presentable a los residentes (peinado, } \\
\text { afeitado, manicura, pedicura). }\end{array}$ \\
\hline & & & 14 & Higiene bucal & $\begin{array}{l}\text { Tiempo empleado en la limpieza de } \\
\text { dientes, encías y boca en general, } \\
\text { para identificar un patrón de tiempo } \\
\text { aplicable a aquellos incapaces de } \\
\text { realizar esta limpieza. }\end{array}$ \\
\hline 5 & Vestirse / Vestirse & & & \multicolumn{2}{|l|}{ Vestirse } \\
\hline \multicolumn{2}{|c|}{$\begin{array}{l}\text { - Consiste en llevar a cabo las } \\
\text { acciones y tareas coordinadas } \\
\text { precisas para ponerse y qui- } \\
\text { tarse la ropa y el calzado en el } \\
\text { orden correcto y de acuerdo } \\
\text { a las condiciones climáticas y } \\
\text { sociales, tales como ponerse, } \\
\text { abrocharse y quitarse la } \\
\text { camisa. }\end{array}$} & $\begin{array}{l}\text { - Reconocer y alcanzar la ropa } \\
\text { y el calzado. } \\
\text { - Calzarse. } \\
\text { - Abrocharse botones o } \\
\text { similar. } \\
\text { - Vestirse las prendas de la } \\
\text { parte inferior del cuerpo. } \\
\text { - Vestirse las prendas de la } \\
\text { parte superior del cuerpo. }\end{array}$ & 15 & Vestirse & $\begin{array}{l}\text { - Levantar: desde que se le comienza } \\
\text { a vestir hasta que se le termina (no } \\
\text { se contempla el acicalamiento). } \\
\text { - Acostar: desde que se le comienza } \\
\text { a desvestir hasta que se le viste con } \\
\text { ropa de cama (pijama, camisón). }\end{array}$ \\
\hline 6 & \multicolumn{2}{|c|}{ Cambiar o mantener la posición del cuerpo / Trasladarse } & & \multicolumn{2}{|l|}{ Transferencias } \\
\hline \multirow{8}{*}{\multicolumn{2}{|c|}{$\begin{array}{l}\text { - Implica adoptar o abandonar } \\
\text { una postura, pasar de un lugar } \\
\text { a otro, como levantarse de } \\
\text { una silla para tumbarse en la } \\
\text { cama, o adoptar o abandonar } \\
\text { posiciones determinadas. }\end{array}$}} & \multirow{8}{*}{$\begin{array}{l}\text { - Pasar de tumbado a sentado } \\
\text { en la cama Permanecer } \\
\text { sentado. } \\
\text { - Pasar de sentado en una silla } \\
\text { a estar de pie. Permanecer } \\
\text { de pie. } \\
\text { - Pasar de estar de pie a } \\
\text { sentado en una silla. } \\
\text { - Transferir el propio cuerpo } \\
\text { mientras se está sentado. } \\
\text { - Transferir el propio cuerpo } \\
\text { mientras se está acostado. } \\
\text { - Cambiar el centro de grave- } \\
\text { dad del cuerpo mientras se } \\
\text { está acostado. }\end{array}$} & 16 & Origen $\cdots$ > silla (grúa) & \multirow{6}{*}{$\begin{array}{l}\text { Desde que se inicia la maniobra en } \\
\text { origen hasta que el residente esté } \\
\text { colocado en destino. Se descontarán } \\
\text { las interferencias producidas por } \\
\text { factores exógenos, excepto las } \\
\text { correspondientes a alteraciones } \\
\text { conductuales. }\end{array}$} \\
\hline & & & 17 & Origen .... s silla (no grúa) & \\
\hline & & & 18 & Origen .... s sillón (grúa) & \\
\hline & & & 19 & Origen .... s sillón (no grúa) & \\
\hline & & & 20 & Origen...$>$ cama (grúa) & \\
\hline & & & 21 & Origen $\cdots$ > cama (sin grúa) & \\
\hline & & & 22 & $\begin{array}{l}\text { Cambios posturales } \\
\text { diurnos }\end{array}$ & \multirow{2}{*}{$\begin{array}{l}\text { Tiempo transcurrido entre el inicio } \\
\text { de la maniobra (abrir cama, retirar } \\
\text { sábanas), la manipulación del cuerpo } \\
\text { y el fin de maniobra (colocar ropa de } \\
\text { cama). }\end{array}$} \\
\hline & & & 23 & $\begin{array}{l}\text { Cambios posturales } \\
\text { nocturnos }\end{array}$ & \\
\hline
\end{tabular}




\begin{tabular}{|c|c|c|c|c|c|}
\hline \multirow{2}{*}{ Cód. } & \multirow{2}{*}{ Ítem (BVD/Barthel) } & \multirow[b]{3}{*}{ / Deambular-escalones } & \multirow{3}{*}{ Cód. } & \multicolumn{2}{|l|}{ Módulo/Componente } \\
\hline & & & & Concepto & Condiciones de medición \\
\hline 7 & Desplazarse dentro hogar / Deambular-escalones & & & \multicolumn{2}{|l|}{ Desplazamiento } \\
\hline \multirow{10}{*}{$\begin{array}{r}- \text { Cor } \\
\text { der } \\
\text { der } \\
\text { alr } \\
\text { zor }\end{array}$} & \multirow{10}{*}{$\begin{array}{l}\text { mprende andar y moverse } \\
\text { ntro de la propia casa, } \\
\text { ntro de una habitación y } \\
\text { ededor de toda la casa o } \\
\text { ha de residencia. }\end{array}$} & \multirow{10}{*}{$\begin{array}{l}\text { - Realizar desplazamientos } \\
\text { para vestirse. } \\
\text { - Realizar desplazamientos } \\
\text { para comer. } \\
\text { - Realizar desplazamientos } \\
\text { para lavarse. } \\
\text { - Realizar desplazamientos no } \\
\text { vinculados al autocuidado. } \\
\text { - Realizar desplazamientos } \\
\text { entre estancias no comunes. } \\
\text { - Acceder a todas las estancias } \\
\text { comunes del hogar. }\end{array}$} & 24 & Origen $\rightarrow \rightarrow$ comedor & \multirow{9}{*}{$\begin{array}{l}\text { Se computará el tiempo transcurrido } \\
\text { en el desplazamiento, acompañado } \\
\text { por una estimación de metros } \\
\text { recorridos. Lógicamente, la medición } \\
\text { temporal de este componente } \\
\text { dependerá de la distribución } \\
\text { arquitectónica del inmueble. }\end{array}$} \\
\hline & & & 25 & Origen $\cdots \rightarrow$ actividades & \\
\hline & & & 26 & $\begin{array}{l}\text { Origen } \rightarrow \text { s peluquería, } \\
\text { podólogo }\end{array}$ & \\
\hline & & & 27 & Origen $\cdots \rightarrow$ salones & \\
\hline & & & 28 & Origen $\cdots$ iglesia & \\
\hline & & & 29 & $\begin{array}{l}\text { Comedor } \rightarrow \text { zona exterior } \\
\text { (jardín) }\end{array}$ & \\
\hline & & & 30 & Origen $\cdots$ s. habitación & \\
\hline & & & 31 & $\begin{array}{l}\text { Origen … WC (según } \\
\text { frecuencia) }\end{array}$ & \\
\hline & & & 32 & Habitación .... WC & \\
\hline & & & 33 & Acostar & $\begin{array}{l}\text { Desde que entra en la habitación, se le } \\
\text { desviste, se le mete en la cama, se le } \\
\text { cambia pañal y se le deja tapado y con } \\
\text { las barras elevadas (si procede). }\end{array}$ \\
\hline
\end{tabular}

\section{Tiempos indirectos}

\begin{tabular}{|c|c|c|c|c|c|}
\hline \multirow{2}{*}{ Cód. } & \multirow{2}{*}{ Ítem (BVD/Barthel) } & \multirow[b]{3}{*}{ o de la salud } & \multirow{3}{*}{ Cód. } & \multicolumn{2}{|l|}{ Módulo/Componente } \\
\hline & & & & Concepto & Condiciones de medición \\
\hline \multirow[t]{6}{*}{8} & Servicios de mantenimiento de la salud & & & \multicolumn{2}{|l|}{ Mantenimiento de la salud } \\
\hline & & \multirow{5}{*}{$\begin{array}{l}\text { - Administración de medica- } \\
\text { ción en ingestas } \\
\text { - Administración de medica- } \\
\text { ción nocturna } \\
\text { - Ejecución de pautas de } \\
\text { pizarras de enfermería } \\
\text { - Estimulación física } \\
\text { - Pulverizar pastillas para } \\
\text { mezcla o disolución } \\
\text { - Servicios de régimen } \\
\text { hostelero }\end{array}$} & 34 & $\begin{array}{l}\text { Administración fármacos } \\
\text { noche }\end{array}$ & \multirow{5}{*}{$\begin{array}{l}\text { Se medirá el tiempo total necesario } \\
\text { para administrar la medicación o } \\
\text { ejecutar pautas y, en cada caso, se } \\
\text { dividirá el tiempo total entre el número } \\
\text { de residentes a los que se les ha } \\
\text { aplicado cada medida, para obtener } \\
\text { un patrón fijo por residente. }\end{array}$} \\
\hline & & & 35 & $\begin{array}{l}\text { Administración fármacos } \\
\text { día }\end{array}$ & \\
\hline & & & 36 & Pautas pizarras & \\
\hline & & & 37 & $\begin{array}{l}\text { Ejercicios bipedestación/ } \\
\text { paseos }\end{array}$ & \\
\hline & & & 38 & Preparación de fármacos & \\
\hline 9 & \multicolumn{2}{|c|}{ Servicios de régimen hostelero } & & \multicolumn{2}{|l|}{ Régimen hostelero } \\
\hline & & \multirow{6}{*}{$\begin{array}{l}\text { - Limpiar y vestir camas } \\
\text { - Preparación de ropa para el } \\
\text { día siguiente } \\
\text { - Depósito de ropa en contene- } \\
\text { dores específicos } \\
\text { - Depósito de lencería de cama } \\
\text { en contenedores } \\
\text { - Limpieza de efectos persona- } \\
\text { les (prótesis, gafas) } \\
\text { - Reposición de pañales }\end{array}$} & 39 & Camas & \multirow{6}{*}{$\begin{array}{l}\text { Se medirá el tiempo total necesario } \\
\text { para realizar cada tarea y, en cada } \\
\text { caso, se dividirá el tiempo total entre } \\
\text { el número de plazas del centro, para } \\
\text { obtener un patrón fijo. }\end{array}$} \\
\hline & & & 40 & Ropa personalizada & \\
\hline & & & 41 & Depósito ropa residente & \\
\hline & & & 42 & Depósito ropa cama & \\
\hline & & & 43 & $\begin{array}{l}\text { Limpieza efectos } \\
\text { personales }\end{array}$ & \\
\hline & & & 44 & $\begin{array}{l}\text { Colocación/reparto } \\
\text { pañales }\end{array}$ & \\
\hline 10 & \multicolumn{2}{|l|}{ Tareas administrativas } & & \multicolumn{2}{|l|}{ Administrativas } \\
\hline & & $\begin{array}{l}\text { Apuntes en el parte de } \\
\text { incidencias }\end{array}$ & 45 & Parte incidencias & \multirow{2}{*}{$\begin{array}{l}\text { Estimación, por observación, del } \\
\text { tiempo dedicado, por término } \\
\text { medio, a la cumplimentación de } \\
\text { la documentación asociada al } \\
\text { desempeño profesional de la auxiliar. }\end{array}$} \\
\hline & & $\begin{array}{l}\text { Cumplimentación de registros } \\
\text { ISO g001 y otros }\end{array}$ & 46 & Registros & \\
\hline
\end{tabular}

Cód.: código.

Fuente: Elaboración propia. 


\section{Diseño del servicio}

Está más que aceptada y justificada la idea de que todos los geriátricos no organizan de idéntica manera su actividad. Si bien todos están acreditados como tales con arreglo a una normativa similar, la gestión de los recursos es prácticamente particular de cada centro. En consecuencia, el primer problema es la definición de un catálogo de tareas/funciones de atención directa que constituya un máximo común denominador de lo que debe entenderse como buenas prácticas en la prestación del servicio. Deberemos desglosar cada intervalo de un día de atención en sus diferentes actividades, y para cada una de ellas, asociar las actividades de la vida diaria (AVD) implícitas en su ejecución. Conforme a un registro para la toma de tiempos previamente definido, mediremos el tiempo de ejecución de cada tarea/función y lo someteremos a control, análisis e interpretación, para que se constituya en uno de los puntos de paso de un determinado perfil de residente.

Todo centro residencial cuenta con el correspondiente programa de atención directa diaria, que se instrumentaliza mediante la definición de tareas y funciones para auxiliares y mediante otros elementos de producción (ayudas técnicas, maquinaria diversa). La realización de cada una de las tareas contenidas en el programa implicará uno o varios módulos. Si se identificaran los módulos presentes en cada actividad, resultaría relativamente sencillo distribuirlos a lo largo de la jornada diaria. De esta manera, se conocerá la dedicación diaria requerida por cada uno de los módulos.

Imaginemos, asimismo, que las actividades diarias se realizan, por término medio, con la secuencia prevista en la programación de la Cuadro 4.

Desarrollar cada una de las actividades descritas en el programa implica la ejecución de uno o varios módulos. Así, la actividad 'vestirse' implica el módulo 'vestido', y la actividad 'desayuno', el módulo ‘alimentación', en una relación biunívoca o unimodular. No obstante, la actividad 'WC' llevará implícitos los módulos 'vestirse', ‘transferencia’, ‘desplazamiento', 'control de esfínteres' e 'higiene personal', en un conjunto de relaciones plurimodulares o unívocas entre módulo y actividad. Por otro lado, también puede afirmarse que dentro de cada actividad existen momentos en que no se pone de manifiesto necesidad alguna de actuar directamente con el residente -necesidad de apoyo de tercera persona para realizar AVD, se entiende-. Estos momentos de actividad no directa, que denominaremos tiempos de supervisión y control, condicionan también el cálculo de tiempos de auxiliar.

Detallar la secuencia de actividades es fundamental, no tanto por detectar qué hace cada modelo organizativo como por contemplar todas las tareas que implícitamente están presentes en cada ítem del Barthel. Lógicamente, a mayor número de tareas, mayor tiempo de auxiliar. Si, como ya se ha indicado, nuestro objetivo final es la estimación de tiempos de auxiliar para cada nivel de dependencia, no debemos obviar, bajo ningún concepto, lo que realmente hacen en su actividad profesional. Consensuar y homogeneizar este 'catálogo de servicios' es la espina dorsal sobre la que se sostiene toda la estructura de nuestro proyecto.

En el Cuadro 1, se extraen 7 de los 10 ítems generales del BVD como aplicables en geriátricos. Dado que el Real Decreto 174/2011 -haciéndose eco de lo que ya recoge la propia CIF de la OMS-define cada uno de ellos, aprovecharemos dicha definición para enmarcar nuestra secuencia de tareas, lo que ya hemos reconocido como máximo común denominador (en el Cuadro 5, se relacionan los ítems del Barthel con las áreas del BVD propias de un servicio residencial para personas mayores).

Continuemos con nuestro razonamiento. Supongamos que las actividades anteriormente relacionadas llevan inherentes la ejecución de distintas tareas que, a su vez, tienen asociados determinados módulos, incluyendo los tiempos de supervisión y control. Podríamos afirmar que cada actividad es un mix, o mezcla de módulos en diferentes cuantías o intensidades (case mix). Obsérvese que hasta el momento

\begin{tabular}{|c|l|c|l|}
\hline \multicolumn{4}{|l|}{ Cuadro 4 Programación diaria, por intervalos temporales } \\
\hline Cód. & Intervalo & Horario & Actividades \\
\hline 1 & $\begin{array}{l}\text { Levantarse - inicio de actividad } \\
\text { matinal }\end{array}$ & $8: 00-10: 30$ & Levantar, asear, acicalar, vestirse, desplazar, desayunar, WC. \\
\hline 2 & $\begin{array}{l}\text { Inicio actividad matinal - fin } \\
\text { actividad matinal }\end{array}$ & $10: 30-12: 30$ & $\begin{array}{l}\text { Gimnasia de mantenimiento, actividades, misa, paseos/bipedestaciones, } \\
\text { ocio y tiempo libre. }\end{array}$ \\
\hline 3 & Fin actividad matinal - fin comida & $12: 30-14: 00$ & Desplazamientos, deambulación, WC, comer, salones. \\
\hline 4 & $\begin{array}{l}\text { Fin comida - inicio actividad } \\
\text { vespertina }\end{array}$ & $14: 00-16: 30$ & $\begin{array}{l}\text { Desplazamientos, aseo/acicalamiento después comida, salón TV, siesta, } \\
\text { merienda, visitas. }\end{array}$ \\
\hline 5 & $\begin{array}{l}\text { Inicio actividad de tarde - fin } \\
\text { actividad vespertina }\end{array}$ & $16: 30-18: 30$ & $\begin{array}{l}\text { Actividades de terapia ocupacional y socio-recreativas, paseos/ } \\
\text { bipedestaciones, ocio y tiempo libre. }\end{array}$ \\
\hline 6 & Fin actividad vespertina - inicio cena & $18: 30-19: 30$ & Desplazamientos, deambulación, WC, salones, actos religiosos. \\
\hline 7 & Inicio cena - fin cena & $19: 30-20: 30$ & Alimentación. \\
\hline 8 & Fin cena - acostar & $20: 30-22: 00$ & Desplazamientos, aseo/acicalamiento después cena, WC, acostar. \\
\hline 9 & Inicio noche - fin noche & $22: 00-8: 00$ & Medicación, cambios posturales, cambios de pañal, recenas. \\
\hline
\end{tabular}

Cód.: código.

Fuente: Elaboración propia. 
no se ha considerado el grado de necesidad del individuo; es decir, los módulos atribuibles a cada tarea no obedecen a una determinada tipología. Es más, de alguna manera estamos presuponiendo una independencia de la composición del mix con respecto al nivel de necesidad del individuo. En otras palabras, cualquiera que sea el nivel de necesidad, la composición modular de cada actividad y, por ende, de cada tarea será siempre la misma. Tres motivos principales aconsejan adoptar este criterio:

- La impresión de que los mix no varían demasiado entre los diferentes usuarios. A priori, podría interpretarse que los módulos son comunes a todas las personas (más o menos, todos nos comunicamos, nos alimentamos o acudimos al baño con determinada frecuencia, dentro de un intervalo de tolerancia), máxime cuando se trata de personas que, por el mero hecho de convivir en un mismo centro, están sometidas a una organización común que origina idénticas rutinas de vida. Las posibles diferencias, de producirse, pueden ser más atribuibles a la propia casuística de la persona que a otros factores, en principio, de dificultosa detección.

- El hecho de que el mix aplicado sea un mix promedio. Aun no siendo exactos, no estarán muy lejos de los valores particulares de cada caso, y el error global no resultará significativo.

- La imposibilidad de trabajar con mix particularizados (implícita en la idea de isogrupo). De lo contrario, la infinidad de posibles combinaciones resultantes pondría en peligro la operatividad del sistema.

Como observación final, resaltaremos que, en algunas actividades, los módulos se desarrollarán de forma consecutiva y preestablecida (por ejemplo, las rutinas diarias asociadas al hecho de levantarse y comenzar el día); en cambio, habrá otras en las que los módulos se encontrarán dispersos de forma casi programada a lo largo de la jornada (desplazamientos a diferentes destinos, como comedores, salas de actividades, patios o jardines exteriores).

\begin{tabular}{|c|c|c|c|c|c|c|c|c|c|c|}
\hline \multicolumn{11}{|c|}{ Cuadro 5. Componentes/tareas implícitas en el trabajo de auxiliar } \\
\hline \multicolumn{2}{|c|}{ Intervalo } & \multicolumn{3}{|c|}{ Tarea } & \multirow[t]{2}{*}{$\mathbf{G}$} & \multirow{2}{*}{$\begin{array}{c}\text { TR } \\
\mathrm{F}\end{array}$} & \multicolumn{2}{|c|}{ Módulo } & \multicolumn{2}{|c|}{ Componente } \\
\hline \multirow{15}{*}{1} & \multirow{15}{*}{$\begin{array}{l}8: 00- \\
10: 30\end{array}$} & 1 & $\begin{array}{l}\text { Comprobación estado } \\
\text { pañal }\end{array}$ & Levantar & & & 2 & Control de esfínteres & 9 & Cambio pañal diurno encamados \\
\hline & & 2 & Transferencia & \begin{tabular}{|l|} 
Pie/cama \\
-silla ruedas
\end{tabular} & • & $\mathrm{F}$ & 6 & Transferencias & 16 & Origen $\cdots \rightarrow$ silla \\
\hline & & 3 & Desvestir & Aseo & & $\mathrm{F}$ & 5 & Vestirse & 15 & Vestirse \\
\hline & & 4 & Desplazamiento & A baño & & $\mathrm{V}$ & 7 & Desplazamiento & 32 & Habitación $\cdots . .$. WC \\
\hline & & 5 & $\begin{array}{l}\text { Ducha/baño (aseo } \\
\text { personal) }\end{array}$ & & & & 3 & Higiene personal & 11 & Ducha o baño \\
\hline & & 6 & Secar e hidratar & & & & 3 & Higiene personal & 11 & Ducha o baño \\
\hline & & 7 & $\begin{array}{l}\text { Ejecutar pautas de } \\
\text { pizarra }\end{array}$ & & & & 8 & Mantenimiento salud & 36 & Pautas pizarras \\
\hline & & 8 & $\begin{array}{l}\text { Peinar, manicura/ } \\
\text { pedicura }\end{array}$ & & & & 4 & Acicalamiento & 13 & Acicalamiento \\
\hline & & 9 & Limpieza bucal & Matinal & & $\mathrm{F}$ & 4 & Acicalamiento & 14 & Higiene bucal \\
\hline & & 10 & Desplazamiento & Habitación & & $\mathrm{V}$ & 7 & Desplazamiento & 30 & Origen $\cdots$... habitación \\
\hline & & 11 & Vestir & Tras aseo & & $\mathrm{F}$ & 5 & Vestirse & 15 & Vestirse \\
\hline & & 12 & Transferencia & $\begin{array}{l}\text { Silla baño } \\
\text {-silla ruedas }\end{array}$ & - & $\mathrm{F}$ & 6 & Transferencias & 16 & Origen $\rightarrow \rightarrow$ silla \\
\hline & & 13 & Desplazamiento & Comedor & & $\mathrm{V}$ & 7 & Desplazamiento & 24 & Origen $\rightarrow>$ comedor \\
\hline & & 14 & Desayunar & & & & 1 & Alimentación & 1 & Desayuno \\
\hline & & 15 & Desplazamiento & Salón & & $\mathrm{V}$ & 7 & Desplazamiento & 25 & Origen $\cdots .>$ actividades \\
\hline \multirow{11}{*}{2} & \multirow{11}{*}{$\begin{array}{l}10: 30- \\
12: 30\end{array}$} & 16 & Desplazamiento & WC & & $\mathrm{v}$ & 7 & Desplazamiento & 31 & Origen.$>\rightarrow$ WC (según frecuencia) \\
\hline & & 17 & Desvestir & WC & & $\mathrm{F}$ & 5 & Vestirse & 7 & WC \\
\hline & & 18 & Sentar en WC & WC & $\bullet$ & $\mathrm{F}$ & 6 & Transferencias & 7 & WC \\
\hline & & 19 & WC & $\begin{array}{l}\text { Durante la } \\
\text { mañana }\end{array}$ & - & $\mathrm{F}$ & 2 & Control de esfínteres & 7 & WC \\
\hline & & 20 & Levantar del WC & WC & $\bullet$ & $\mathrm{F}$ & 6 & Transferencias & 7 & WC \\
\hline & & 21 & Vestir & WC & & $\mathrm{F}$ & 5 & Vestirse & 7 & WC \\
\hline & & 22 & Transferencia & $\begin{array}{l}\text { De pie/grúa } \\
\text { a silla }\end{array}$ & - & $\mathrm{F}$ & 6 & Transferencias & 16 & Origen $\cdots . .>$ silla \\
\hline & & 23 & Desplazamiento & Salón & & $\mathrm{V}$ & 7 & Desplazamiento & 27 & Origen $\rightarrow \rightarrow$ salones \\
\hline & & 24 & Transferencia & De silla a pie & $\bullet$ & $\mathrm{F}$ & 6 & Transferencias & 37 & Ejercicios bipedestación/paseos \\
\hline & & 25 & \begin{tabular}{|l|} 
Paseos/ \\
bipedestaciones
\end{tabular} & $\begin{array}{l}\text { Ejercicio de } \\
\text { mañana }\end{array}$ & & V & 7 & Desplazamiento & 37 & Ejercicios bipedestación/paseos \\
\hline & & 26 & Transferencia & De pie a silla & $\bullet$ & $\mathrm{F}$ & 6 & Transferencias & 37 & Ejercicios bipedestación/paseos \\
\hline \multirow[b]{2}{*}{3} & \multirow[b]{2}{*}{$\begin{array}{l}12: 30- \\
14: 00\end{array}$} & 27 & Desplazamiento & Comedor & & $\mathrm{V}$ & 7 & Desplazamiento & 24 & Origen $\rightarrow \rightarrow$ comedor \\
\hline & & 28 & Comer & $\begin{array}{l}\text { Almuerzo o } \\
\text { comida }\end{array}$ & & $\mathrm{F}$ & 1 & Alimentación & 2 & Comida \\
\hline
\end{tabular}




\begin{tabular}{|c|c|c|c|c|c|c|c|c|c|c|}
\hline \multicolumn{2}{|c|}{ Intervalo } & \multicolumn{3}{|c|}{ Tarea } & \multirow[t]{2}{*}{ G } & \multirow{2}{*}{$\frac{T R}{V}$} & \multicolumn{2}{|c|}{ Módulo } & \multicolumn{2}{|c|}{ Componente } \\
\hline \multirow{16}{*}{4} & \multirow{16}{*}{$\begin{array}{l}14: 00- \\
16: 30\end{array}$} & 29 & Desplazamiento & Sillón siesta & & & 7 & Desplazamiento & 27 & Origen $\ldots . .>$ salones \\
\hline & & 30 & Transferencia & Silla a sillón & $\bullet$ & $\mathrm{F}$ & 6 & Transferencias & 18 & Origen $\ldots .$. s sillón \\
\hline & & 31 & Limpieza bucal & Comida & & $\mathrm{F}$ & 4 & Acicalamiento & 14 & Higiene bucal \\
\hline & & 32 & Transferencia & Sillón a silla & $\bullet$ & $\mathrm{F}$ & 6 & Transferencias & 16 & Origen $\cdots . .>$ silla \\
\hline & & 33 & Desplazamiento & WC & & V & 7 & Desplazamiento & 31 & Origen $\cdots \rightarrow$ WC (según frecuencia) \\
\hline & & 34 & Desvestir & WC & & $\mathrm{F}$ & 5 & Vestirse & 7 & WC \\
\hline & & 35 & Sentar en WC & WC & $\bullet$ & $\mathrm{F}$ & 6 & Transferencias & 7 & WC \\
\hline & & 36 & WC & $\begin{array}{l}\text { Durante la } \\
\text { tarde }\end{array}$ & & $\mathrm{F}$ & 2 & Control de esfínteres & 7 & WC \\
\hline & & 37 & $\begin{array}{l}\text { Comprobación estado } \\
\text { pañal }\end{array}$ & WC & & $\mathrm{F}$ & 2 & Control de esfínteres & 7 & WC \\
\hline & & 38 & Levantar del WC & WC & $\bullet$ & $\mathrm{F}$ & 6 & Transferencias & 7 & WC \\
\hline & & 39 & Vestir & WC & & $\mathrm{F}$ & 5 & Vestirse & 7 & WC \\
\hline & & 40 & Transferencia & A silla & $\bullet$ & $\mathrm{F}$ & 6 & Transferencias & 16 & Origen $\ldots . .$. silla \\
\hline & & 41 & Desplazamiento & Salón & & V & 7 & Desplazamiento & 27 & Origen $\ldots . .>$ salones \\
\hline & & 42 & Merendar & & & & 1 & Alimentación & 3 & Merienda \\
\hline & & 43 & Hidratación oral & & & & 1 & Alimentación & 3 & Merienda \\
\hline & & 44 & Desplazamiento & Salón & & V & 7 & Desplazamiento & 27 & Origen....$>$ salones \\
\hline \multirow{3}{*}{5} & \multirow{3}{*}{$\begin{array}{l}16: 30- \\
18: 30\end{array}$} & 45 & Transferencia & Silla a pie & $\bullet$ & $\mathrm{F}$ & 6 & Transferencias & 37 & Ejercicios bipedestación/paseos \\
\hline & & 46 & $\begin{array}{l}\text { Paseos/ } \\
\text { bipedestaciones }\end{array}$ & $\begin{array}{l}\text { Ejercicio de } \\
\text { tarde }\end{array}$ & & V & 7 & Desplazamiento & 37 & Ejercicios bipedestación/paseos \\
\hline & & 47 & Transferencia & Pie - silla & $\bullet$ & $\mathrm{F}$ & 6 & Transferencias & 37 & Ejercicios bipedestación/paseos \\
\hline \multirow[t]{2}{*}{6} & \multirow{2}{*}{$\begin{array}{l}18: 30- \\
19: 30\end{array}$} & 48 & Desplazamiento & $\begin{array}{l}\text { Supervisión } \\
\text { salones }\end{array}$ & & V & 7 & Desplazamiento & 27 & Origen....$>$ salones \\
\hline & & 49 & Desplazamiento & Comedor & & $\mathrm{V}$ & 7 & Desplazamiento & 24 & Origen..$>$ comedor \\
\hline 7 & $\begin{array}{l}19: 30- \\
20: 30\end{array}$ & 50 & Comer & Cena & & $\mathrm{F}$ & 1 & Alimentación & 4 & Cena \\
\hline \multirow{5}{*}{8} & \multirow{5}{*}{$\begin{array}{l}20: 30- \\
22: 00\end{array}$} & 51 & Desplazamiento & Habitación & & V & 7 & Desplazamiento & 30 & Origen.... habitación \\
\hline & & 52 & Desvestir & Acostar & & $\mathrm{F}$ & 5 & Vestirse & 15 & Vestirse \\
\hline & & 53 & Limpieza bucal & Acostar & & $\mathrm{F}$ & 4 & Acicalamiento & 14 & Higiene bucal \\
\hline & & 54 & Transferencia & Silla a cama & $\bullet$ & $\mathrm{F}$ & 6 & Transferencias & 20 & Origen $\ldots . .>$ cama \\
\hline & & 55 & Acostar & & & & 7 & Desplazamiento & 33 & Acostar \\
\hline
\end{tabular}

G: grúa. TR: tipo de repetición en las tareas (F: fijas / V: variables). Fuente: Elaboración propia.

\section{Ponderaciones de los niveles de necesidad de ayuda}

En el índice Barthel, la dependencia se clasifica en cinco niveles: total, grave, moderada, leve e independiente. La experiencia demuestra que una misma puntuación no se traduce en idénticas cargas de trabajo directa para satisfacer las necesidades en las actividades de la vida diaria, lo que plantea la idea de que los niveles de ayuda son relativos, y no absolutos.

El coeficiente del tipo de apoyo de otra u otras personas (Tabla 1) corrige los pesos relativos de cada ítem del Baremo de Valoración de la Dependencia para asignar un cómputo de puntos en función del nivel de desempeño y, consecuentemente, ubicar a la persona valorada en uno de los tres grados de dependencia predefinidos: moderada (puntuación total de entre 25 y 49 puntos), severa (entre 50 y 74 puntos) y gran dependencia (más de 74 puntos). Pero una cosa es conocer la discapacidad y -en función del desempeño de cada cual- la dependencia, y otra derivar de dichas puntuaciones tiempos estándar de ayuda de tercera persona para la realización de las actividades de la vida diaria. Definir pasarelas directas entre unas y otras es despreciar evidencias empíricas, como el estado cambiante de las personas cuidadas y de sus cuidadores (ánimo, colaboración, empatía, paciencia) o lo que Knapp (1988) define como recursos intangibles.

\subsection{Conceptos de discapacidad, deficiencia y dependencia}

En este punto, conviene definir algunos conceptos utilizados en el estudio:

- Discapacidad: término genérico que incluye deficiencias, limitaciones en la actividad y restricciones en la participación. Indica los aspectos negativos de la interacción entre el individuo (con una determinada condición de salud) y sus factores contextuales (socioambientales).

- Deficiencia: anormalidad o pérdida de una estructura o de una función corporal.

- Dependencia: situación en la que una persona con discapacidad precisa de ayuda, técnica o personal, para la realización de una determinada actividad o la mejora del rendimiento funcional. 
- Actividad: realización de una tarea o acción por una persona, en su casa, su lugar de trabajo o estudio, o cualquier otro espacio. Representa la perspectiva del individuo respecto al funcionamiento.

- Limitación en la actividad: dificultad que un individuo puede tener para realizar una actividad. La desviación se gradúa entre leve y grave en términos de cantidad y calidad, comparándola con la manera, extensión o intensidad en que se espera que la realizaría una persona sin esa condición de salud. Representa la perspectiva del individuo respecto a la discapacidad.

Nuestro objetivo como organizaciones que prestan servicios integrales en régimen residencial para personas mayores no es clasificar personas, sino los problemas que éstas tienen. Clasificar problemas y responder a ellos es algo que indefectiblemente deben plantarse los geriátricos, porque, en definitiva, es parte esencial de su actividad profesional. Además, deberían hacerlo en términos de eficiencia. Por su parte, clasificar personas es competencia de la Administración si entre sus planes pretende asignar tarifas en función de los recursos realmente consumidos por un perfil tipo (isogrupo).

\subsection{Nivel de dependencia (necesidad de ayuda)}

En consonancia con lo que propugna la OMS, podemos definir los niveles de gravedad que puede presentar un residente para el desarrollo de las actividades de la vida diaria (AVD) como el porcentaje de dependencia o de necesidad de ayuda (técnica o personal) para la realización de esa actividad. La propuesta de la CIF es aplicar una misma escala genérica de gravedad en cinco niveles para todos los componentes (funciones y estructuras corporales, actividades y participación, y factores contextuales). Tener un problema puede significar tanto una deficiencia como una limitación, restricción o barrera, dependiendo de lo que estemos clasificando (Querejeta, 2004). Si recordamos los niveles de gravedad propuestos por la CIF (Tabla 1), interpretamos con claridad lo siguiente: un usuario que presenta un nivel de gravedad moderado en el módulo $x$ requerirá de la asistencia exclusiva de auxiliar de geriatría entre un $25 \%$ y un $49 \%$ de las veces en que la necesidad se presenta a lo largo del día. Naturalmente, el porcentaje de atención directa, aun cuando en la práctica lo asociamos a unos intervalos determinados, es una variable continua en el intervalo 0-100\%.

Nuestro objetivo último es particularizar los niveles de gravedad/necesidad para cada residente y módulo (no olvidemos que medimos dependencia, y no discapacidad ni deficiencia). Para una deficiencia muy grave en alimentación, por ejemplo, las carencias serán cubiertas mínimamente por una auxiliar y fundamentalmente por algún procedimiento alternativo -bombas de alimentación, sonda nasogástrica o gastrostomía en casos de coma vigil o problemas de deglución-; para deficiencias menores, con el objetivo de una posible recuperación del hábito, se requerirá una mayor intensidad en el apoyo externo (complementar su deficiencia en el uso y manejo de cubiertos, incrementar sus habilidades para las rutinas propias de la actividad -cortar carne, untar, servirse-). En un módulo como 'alimentación', la correspondencia entre autonomía y discapacidad no es ni puramente directa ni continuamente inversa.

Si se evalúa la necesidad de ayuda de tercera persona independientemente del contexto en el que se desenvuelve el usuario -entendiendo por contexto elementos como las ayudas técnicas que mejoren su autonomía, el diagnóstico o el espacio social- podría sesgarse positivamente el cálculo del tiempo de auxiliar. No debemos valorar igualmente a dos usuarios que, siendo graves desde el punto de vista de la deficiencia, no lo son desde el punto de vista de demanda de ayuda de tercera persona. En consecuencia, los puntos Barthel deben corresponderse con la demanda de necesidad de ayuda de tercera persona por parte del usuario y no, como en principio cabría esperar, con el nivel de gravedad en cuanto a su deficiencia se refiere (idea de desempeño que contempla el BVD, a sugerencia de la CIF). Así, podemos interpretar que la relación entre nivel de gravedad/dependencia y tiempo de auxiliar será creciente, mientras que la línea que une el nivel de discapacidad y el tiempo de auxiliar podría adoptar una de las dos formas siguientes:

- Relación directa entre el tiempo de auxiliar y el nivel de discapacidad: se caracteriza porque a medida que el usuario presenta mayor gravedad, aumenta el porcentaje de dedicación del tiempo de auxiliar. Un ejemplo claro de este módulo es 'control de esfínteres'.

- Relación variable entre el tiempo de ayuda de tercera persona y el nivel de discapacidad: se suceden, indistintamente, pendientes positivas y negativas, en la función que une ambas variables; es decir, a una mayor o menor gravedad, no tienen por qué corresponderse, respectivamente, una mayor o menor dedicación de auxiliar. Ejemplos de esta relación podrían ser módulos como 'alimentación' o 'desplazamiento'. Las ayudas técnicas de toda índole incrementan la autonomía del usuario, llegando incluso a hacerle autónomo en determinadas actividades y bajo condiciones específicas. Así, un usuario con 10 puntos Barthel en el módulo ‘desplazamiento' (necesita ayuda física o supervisión para caminar 50 metros) podría necesitar mayor tiempo de auxiliar que uno con 5 puntos (independiente en silla de ruedas sin ayuda) en silla de ruedas, pero cognitivamente capaz de deambular libremente por un espacio sin barreras arquitectónicas.

Por su parte, una hipotética relación inversa entre el tiempo modular y el grado de discapacidad es teóricamente posible, pero muy improbable en los geriátricos vascos, y, en todo caso, se correspondería con estados vegetativos en los que los estímulos para colaborar no producen respuestas positivas y, 


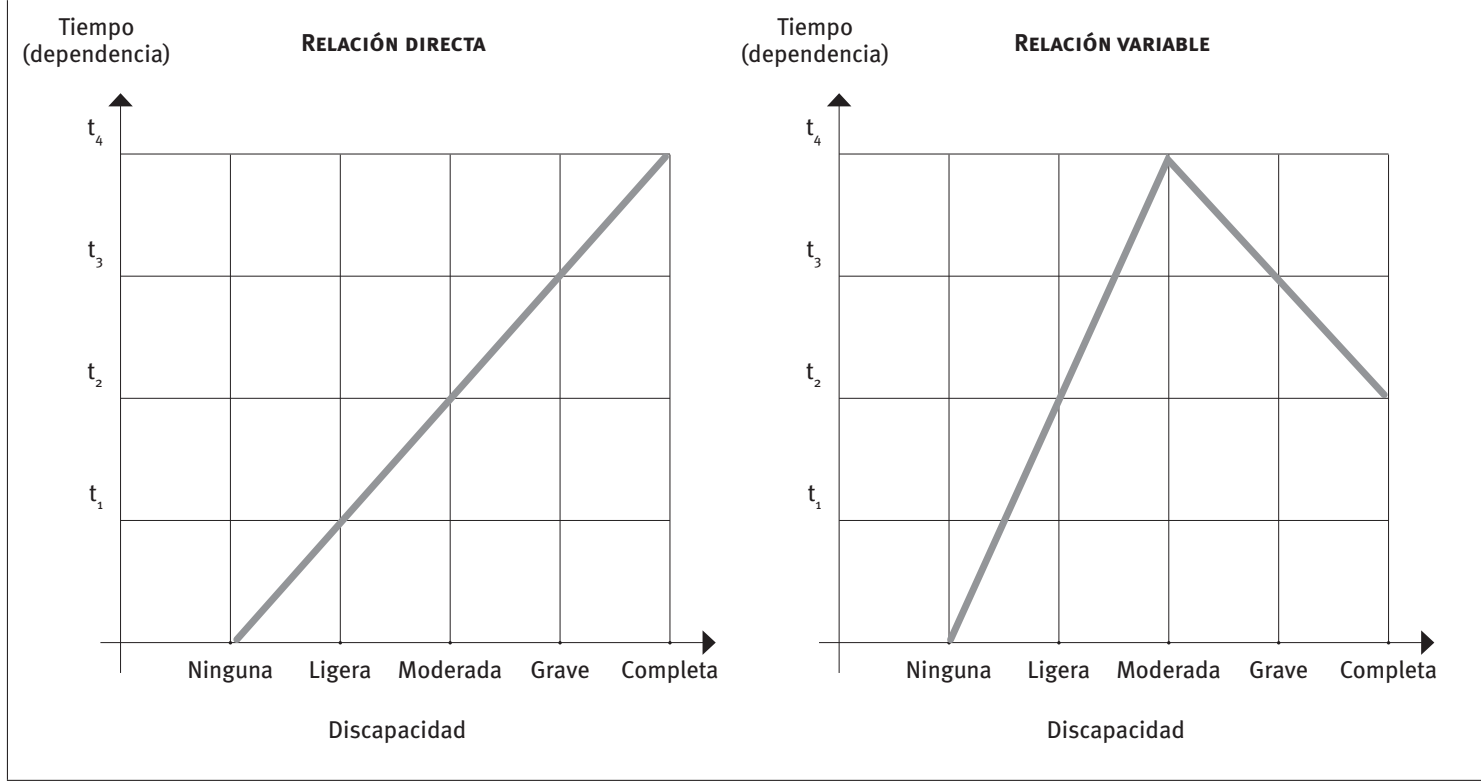

Fuente: Elaboración propia.

en consecuencia, los tiempos de auxiliar dependen fundamentalmente de la propia experiencia del profesional y su conocimiento del residente. En la medida que, en estos casos, no se trata de mantener la potencialidad del residente, es posible que a mayor dependencia, se requiera menor tiempo de auxiliar (Gráfico 1).

En consecuencia, es imprescindible contar con una valoración coherente con el contexto del usuario, para disponer de una herramienta capaz de estimar tiempos de auxiliar que se correspondan con la demanda real de atención que presenta el usuario. Un objetivo que hace propio, por otra parte, la OMS en la Clasificación Internacional del Funcionamiento, de la Discapacidad y de la Salud, donde cambia términos como 'discapacidad' y 'minusvalía' por ‘actividad' y 'participación', respectivamente, con el ánimo de situarse en posiciones positivistas, medidoras de las capacidades de los usuarios y no de sus impedimentos o incapacidades.

\section{Ratios de auxiliar de geriatría}

\subsection{Ratio real y ratio teórica}

El objetivo del presente apartado es la medición de la ratio de auxiliar y sus implicaciones en el coste/ plaza. Este indicador relaciona el número de profesionales necesarios para la atención de un número concreto de usuarios con unos determinados perfiles. Es decir, su cálculo se corresponde con una determinada realidad: en la medida que ésta cambia, la ratio debe reaccionar ante la nueva configuración.

Expresemos matemáticamente la ratio real de auxiliar como sigue:

$$
r_{r}=\frac{\frac{\sum_{r=1}^{n} h_{r}}{n}}{\text {, donde }}
$$

- $\sum h_{r}$ : horas de trabajo de auxiliar necesarias para la atención del conjunto de residentes; es daecir, desde el trabajador 1 hasta el trabajador $n$, cada uno con su propia jornada anual.

- j: jornada anual correspondiente a la indicada en el marco laboral de referencia (convenio colectivo o pacto de empresa).

- n: número de usuarios (normalmente, coincidirá con la capacidad del centro).

Los cálculos de tiempos modulares se refieren a un día promedio de atención, obtenido para una determinada modalidad de servicio (programa de actividades diarias y tareas implícitas en él). Trabajar con perfiles personalizados supondría aplicar todo el procedimiento de cálculo de tiempos de auxiliar a la situación particular de cada usuario, con lo que la enorme cantidad de posibles combinaciones convertiría la tarea administrativa correspondiente en algo impensable de plantear a la Administración. No obstante, en cuanto a gestión interna, no deberíamos tener problemas si contamos con una herramienta informática ad hoc que garantice un cálculo fiable y estadísticamente significativo, por numerosos que fueran los perfiles que hubiera que combinar.

Queremos desarrollar un procedimiento de cálculo de ratios para perfiles determinados. Pero éstos cambian en la medida que lo hace cualquiera de los 
elementos que lo integran, y también en función del índice de rotación del centro, que, a su vez, dependerá, entre otras cosas, de la gestión de las listas de espera. Obsérvese que los perfiles de alta no tienen por qué coincidir con los perfiles de baja. En consecuencia, si en la expresión anterior sustituimos $h_{r}$ por $h_{t,}$ o total de horas necesarias para atender a los usuarios de cada centro en función de perfiles personalizados, obtendríamos la ratio teórica de auxiliar $(r)$. Comparando ambas ratios, se dan las posibilidades de la Tabla 2.

\section{Tabla 2. Ratios teóricas y ratios reales}

\begin{tabular}{|l|l|}
\hline Condición & Interpretación \\
\hline$r_{r}>r_{t} \times(1+0,03)$ & $\begin{array}{l}\text { Horas necesarias por encima de } \\
\text { las teóricas corregidas al alza } \\
\text { con margen de tolerancia (3\%). } \\
\text { Dependerá de los resultados } \\
\text { de la supervisión del trabajo } \\
\text { de auxiliares considerar o no } \\
\text { la modificación de las ratios } \\
\text { teóricas. }\end{array}$ \\
\hline$r_{t} \times(1-0,03) \leq r_{r} \leq r_{t} \times(1+0,03)$ & $\begin{array}{l}\text { Horas necesarias, dentro del } \\
\text { intervalo de tolerancia, respecto } \\
\text { a las horas teóricas. }\end{array}$ \\
\hline & $\begin{array}{l}\text { Horas necesarias por debajo de } \\
\text { las teóricas corregidas a la baja } \\
\text { con margen de tolerancia (3\%). } \\
\text { Dependerá de los resultados } \\
\text { de la supervisión del trabajo } \\
\text { de auxiliares catalogar la ratio } \\
\text { como eficiencia, mal hábito, } \\
\text { error o no conformidad }\end{array}$ \\
\hline$r_{r}<r_{t} \times(1-0,03)$ &
\end{tabular}

$r_{r}$ : ratio real. $r_{t}$ : ratio teórica.

Fuente: Elaboración propia.

\subsection{Interpretación del perfil promedio (case mix)}

No es desacertado considerar la definición de un perfil promedio como representativo de la dispersión de perfiles de usuario en un centro. Sin embargo, el perfil promedio no debe indicar cuál es su composición modular, es decir, no requiere detallar si una u otra categoría es combinación de tantos o cuantos usuarios con niveles de gravedad ligeros, moderados, graves o completos; ni mucho menos debería decir absolutamente nada de los usuarios en lista de espera. En este contexto, no conocemos hacia dónde vamos y, por tanto, las ratios válidas hoy podrían dejar de serlo a corto o medio plazo. El perfil promedio no constituye sino una foto, en un momento determinado, de lo que interpretamos como usuario tipo de un centro, y debe servir para poder comparar unos centros con otros y, a su vez, con la media del sector 0 , al menos, con la del grupo de estudio. Lógicamente, la eficacia de los tiempos compartidos para los perfiles promedios debe estar basada en el rigor de las supervisiones realizadas.

\subsection{Ratio dinámica y ratio estática}

El estudio histórico de los perfiles, tanto de usuarios con plaza como de potenciales usuarios en lista de espera, debe reflejar el carácter dinámico del sector, del que en ningún caso nos debemos abstraer. Porque los perfiles no son constantes en el tiempo: pueden mejorar $-y$, bajo determinadas circunstancias, así debería ser, si la entidad presta sus servicios con calidad y eficiencia- o pueden empeorar -por enfermedades crónicas degenerativas, por ejemplo-. Y porque, además, la previsión que se haga de futuros usuarios a partir de la lista de espera, o el análisis de las demandas de servicios residenciales, puede hacer que las empresas prestatarias de servicios tengan que modificar sus plantillas de personal.

Conocido el tamaño de cada estrato de nuestra población en cuanto a consumos homogéneos se refiere (isogrupo), podremos valorar la ratio de auxiliar desde una doble perspectiva:

- Ratio estática: si este indicador es considerado fijo en un periodo (un año natural, por ejemplo), la sustitución de las bajas debe realizarse dentro de un mismo compartimento si lo que buscamos es preservar la idoneidad de la ratio. Claro está que sólo con ratios estáticas podremos garantizar la correspondencia entre ratios teóricas y reales.

- Ratio dinámica: no obstante, en no pocas ocasiones, las listas de espera se priorizan con otros criterios, asignando usuarios de isogrupos que no se corresponden con las bajas. En estas circunstancias, la correspondencia se incumple y la ratio ya no es representativa de la nueva configuración del perfil medio, lo que obligaría a recalcularla.

Habrá que ponderar, pues, las consecuencias, en costes, de la adscripción de usuarios a los servicios concertados. No olvidemos que, en última instancia, una técnica basada en la metodología case mix tiene como objetivo la fijación de unos costes estándares para unas determinadas tipologías, y que éstos cambian en la medida que cambian sus componentes.

\section{Muestreo, medición de tiempos y tiempo total necesario}

\subsection{Tamaño de muestra}

¿Cuánto individuos integran la muestra? ¿Todos? Si no fuera así, ¿qué parte? Aproximadamente 2.000 residentes podrían configurar la población de nuestro estudio (Tabla 3).

Tabla 3. Población de estudio

\begin{tabular}{|l|c|}
\hline Residencia & Plazas \\
\hline Fundación Zorroaga (Donostia, Gipuzkoa) & 300 \\
\hline Nuestra Señora de la Paz (Donostia, Gipuzkoa) & 75 \\
\hline Aita Menni (Durango y Bilbao, Bizkaia) & 341 \\
\hline Fundación Aspaldiko (Portugalete, Bizkaia) & 280 \\
\hline Santa y Real Casa de Misericordia de Bilbao (Bizkaia) & 215 \\
\hline Fundación Miranda (Barakaldo, Bizkaia) & 229 \\
\hline Santa y Real Casa de Misericordia de Pamplona (Navarra) & 585 \\
\hline Total de plazas & 2.025 \\
\hline
\end{tabular}

Fuente: Elaboración propia. 
Aplicar el registro de toma de tiempos (véase el apartado 8.2.6.) a todas y cada una de las personas residentes dilataría en exceso tanto el tiempo de trabajo de campo como el coste asociado. En consecuencia, si aceptamos la hipótesis de la correspondencia entre BVD y Barthel, para determinar una muestra representativa del comportamiento de la población deberían tenerse en cuenta las siguientes consideraciones:

- Desconocemos a priori de los parámetros de la población (media y desviación típica).

- No es procedente la definición de una muestra que permita estimar dichos parámetros cuando los componentes de aquélla podrían formar parte, a su vez, de la muestra definitiva (dicho de otra manera, es ilógico definir una pre-muestra para obtener una muestra).

- Como desconocemos la desviación estándar de la población, cifraremos su valor tipificado en 0,5 (lo que asegura un tamaño suficientemente representativo).

- Trabajaremos con márgenes de error $\left(\bar{X}-\mu_{x}\right) \leq 3 \%$ para niveles de confianza generalmente aceptados $(Z \geq 1,96)$ en diferentes referencias bibliográficas.

El tamaño de muestra global resultante para una población de 2.000 elementos vendrá determinado por la sustitución de los valores correspondientes en $n=\frac{N_{p}}{1+\frac{\left(\bar{X}-\mu_{X}\right)^{2}\left(N_{p}-1\right)}{Z^{2}\left(S^{\prime}\right)^{2}}} \cdot$

Así, para diferentes combinaciones de $\left(\bar{X}-\mu_{x}\right)$ y $Z$, obtendremos los tamaños de muestra de la Tabla 4.

Tabla 4. Tamaños de muestra

\begin{tabular}{|c|c|c|}
\hline$\left(\bar{X}-\mu_{x}\right)$ & $\mathbf{Z}$ & Tamaño muestral \\
\hline $1 \%$ & 2,58 & 1.786 \\
\hline $3 \%$ & 2,17 & 793 \\
\hline $5 \%$ & 1,96 & 322 \\
\hline
\end{tabular}

Fuente: Elaboración propia.

Se entiende suficiente trabajar con un margen de error del $3 \%$ para un nivel de confianza del $97 \%$ (la media de la población no se aleja, en términos relativos, más de un $3 \%$ de la media de la muestra en un $97 \%$ de los casos). A priori, trabajar con errores muestrales superiores supondría referenciar las ratios de personal sobre estadísticos de consistencia insuficiente, que, a su vez, darían lugar a tiempos de atención directa con un nivel de dispersión por encima del que estamos dispuestos a tolerar. Acotar el error muestral a un $3 \%$ garantiza ratios certeras, que no añaden una dispersión significativa a una realidad dispersa de por sí, además de ajustar los costes derivados de la labor de campo a los recursos disponibles.

Dado que, como ya hemos comentado, no conocemos nada acerca del comportamiento de la población, pero sí sabemos que la dependencia podría estar dividida en tramos (por ejemplo, autónomo, dependiente y gran dependiente), sería aconsejable que, al menos, la muestra total tuviera representación proporcional con arreglo al peso específico de cada nivel de dependencia sobre el total de la población. En esta circunstancia, a falta de mayor conocimiento, la muestra debería estar estratificada, tal y como indica la expresión $n_{e}=n \cdot \frac{N_{e}}{N_{p}}$. Cuando obtengamos datos empíricos, podremos estimar de manera más concreta los parámetros de la población.

Recordemos que, dado que la población se divide en 3 estratos bien diferenciados según la propia sectorización del BVD (por ejemplo, en Gipuzkoa se consideran autónomos aquellos residentes con menos de 25 puntos; dependientes, aquéllos con entre $25 \mathrm{y}$ 49 puntos; y grandes dependientes quienes tienen al menos 50 puntos), la muestra deberá ser sensible a condicionantes similares. Como desconocemos la desviación de cada estrato, la composición de la muestra deberá contar con representación, al menos, proporcional de cada uno de ellos $\left(n_{e}=n \cdot \frac{N_{e}}{N_{p}}\right)$. Así, suponiendo que los datos de cada centro sean los que figuran en la Tabla 5, cada uno de ellos participará en la muestra total conforme a la expresión de $n_{e}$, que, además, será proporcional también al tamaño total los centros.

Para determinar la configuración de la muestra de cada centro, previamente debemos conocer la distribución de las valoraciones Barthel de sus residentes. Evidentemente, si no dispusiéramos de éstas, habría que administrar la escala; en caso contrario, se darían por válidas aquéllas cuya valoración no fuera anterior a seis meses desde la fecha prevista de medición y que, en todo caso, a juicio del profesional competente, no hayan experimentado una evolución que justificara una nueva evaluación. No olvidemos que la valoración Barthel debe ir acompañada, para determinados ítems, de una ponderación adecuada del nivel de dependencia, conforme a los niveles de gravedad propuestos por la CIF-OMS. 
Tabla 5. Simulación de la muestra estratificada, por niveles de dependencia*

\begin{tabular}{|c|c|c|c|c|c|c|c|c|c|c|}
\hline \multirow{3}{*}{ Centro } & \multirow{3}{*}{ Tamaño } & \multicolumn{9}{|c|}{ Distribución de categorías } \\
\hline & & \multicolumn{3}{|c|}{$A(B=100)$} & \multicolumn{3}{|c|}{$D(80 \leq B \leq 99)$} & \multicolumn{3}{|c|}{ GD $(B \leq 79)$} \\
\hline & & no & $\%$ & $n_{1 i}$ & no & $\%$ & $n_{1 i}$ & no & $\%$ & $n_{1 i}$ \\
\hline 1 & 59 & 1 & 1,7 & 0 & 15 & 25,4 & 6 & 43 & 72,9 & 17 \\
\hline 2 & 300 & 45 & 15,0 & 18 & 80 & 26,7 & 32 & 175 & 58,3 & 69 \\
\hline 3 & 215 & 24 & 11,2 & 10 & 48 & 22,3 & 19 & 143 & 66,5 & 56 \\
\hline 4 & 280 & 32 & 11,4 & 13 & 61 & 21,8 & 24 & 187 & 66,8 & 74 \\
\hline 5 & 229 & 13 & 5,7 & 5 & 63 & 27,5 & 25 & 153 & 66,8 & 60 \\
\hline 6 & 341 & 10 & 2,9 & 4 & 45 & 13,2 & 18 & 286 & 83,9 & 113 \\
\hline 7 & 585 & 72 & 12,3 & 28 & 121 & 20,7 & 47 & 392 & 67,0 & 155 \\
\hline Total (N) & 2.009 & 197 & 9,8 & - & 433 & 21,6 & - & 1.379 & 68,6 & - \\
\hline Muestra (n) & 793 & 793 & - & 62 & - & - & 150 & - & - & 452 \\
\hline $\begin{array}{c}\text { Error muestral } \\
(\%)\end{array}$ & 3 & & & & & & & & & \\
\hline $\begin{array}{c}\text { Nivel confianza } \\
(\%)\end{array}$ & 97 & & & & & & & & & \\
\hline
\end{tabular}

* Los datos que figuran en la tabla no se corresponden con la realidad. Su sentido es simular la composición de la muestra. A: autónomo. D: dependiente. GD: gran dependiente. B: índice Barthel.

Fuente: Elaboración propia.

\subsection{Metodología para la selección de elementos (residentes) de cada estrato}

Ya hemos definido el tamaño de cada estrato. Ahora bien, ¿qué procedimiento aplicaremos en la medición del tiempo asignado a cada componente para maximizar la productividad del equipo de medidores? Desde luego, la propia dinámica de cada centro condicionará las posibilidades de medición de acuerdo al patrón definido. Si, como hemos considerado, se presume que la variabilidad se produce tanto entre perfiles diferentes como en un mismo perfil en el tiempo, los elementos que compongan la muestra deberían contemplar este hecho. Sin referencias bibliográficas claras y concisas al respecto, desde la propia experiencia debemos ser capaces de dar sentido a las consecuencias que podrían plantearse las siguientes condiciones:

- Validar las mediciones considerando el análisis de las desviaciones observadas en los resultados obtenidos por distintos medidores sobre un mismo sujeto (objetividad de la medición).

- Medir la dispersión que puede presentar un mismo residente con un mismo auxiliar en distintos momentos y en una misma situación asistencial (sin cambios presumibles en su valoración Barthel).

\subsubsection{Validación del sistema de medición}

Ya hemos concluido que la producción de servicios residenciales es una tarea en la que cada output es normalmente distinto del anterior, y aun cuando aparentemente fueran iguales, cada uno de ellos necesita una composición diferente. En consecuencia, reservaremos una parte de la muestra para comprobar esta hipótesis y estimar hasta qué punto los recursos intangibles que defiende Knapp (1988) -el ánimo, las alteraciones conductuales o el conocimiento- sesgan positiva o negativamente el tiempo necesario de auxiliar de geriatría. El problema radica, no obstante, en que si bien la medición de un mismo residente en diferentes momentos es factible, la posibilidad de que dos medidores distintos realicen mediciones de un mismo residente bajo idénticas condiciones no parece posible si nuestra hipótesis plantea que dicho residente es aleatoriamente cambiante. Si por experimento aleatorio entendemos aquel que, bajo un mismo conjunto aparente de condiciones iniciales, puede presentar resultados diferentes (en otras palabras, no podríamos predecir o reproducir el resultado exacto de cada experiencia en particular), en la medida que las condiciones particulares del residente, e incluso del profesional que lo atiende, no son estables por acción de factores exógenos e intangibles, la validación del método de medición no puede ser demostrada por significación estadística. Se entiende que pretender demostrar, a través de técnicas estadísticas de correlación entre variables, que los resultados obtenidos en dos muestras distintas correspondientes a dos medidores diferentes con los mismos usuarios están directamente asociadas (esto es, que sus diferencias, si existieran, se deben fundamentalmente al azar) podría requerir, a su vez, del cumplimiento de una serie de hipótesis difícilmente comprobables y practicables de modo común:

- Todos y cada uno de los medidores aplican la metodología con la misma fidelidad respecto a las pautas definidas.

- Todos y cada uno de los auxiliares tienen idéntica pericia, destreza y, en definitiva, experiencia en el desarrollo de su actividad profesional.

- Las características organizativas, físicas (distribución del inmueble) y tecnológicas (ayudas técni- 
cas y otras tecnologías) de las organizaciones son similares.

Por todo ello, el grupo de trabajo debe asegurar que los medidores se esfuercen en aplicar puntualmente las instrucciones remitidas respecto a qué y de qué manera se debe medir. Si velamos por que así sea, minimizaremos los sesgos procedentes de causas realmente aleatorias. Quizás no podamos validar estadísticamente el sistema de medición, pero en todo caso aseguraremos que cualquiera que sea el resultado obtenido lo es de igual manera en todos y cada uno de los centros que componen la muestra. No olvidemos que el fin último de este estudio es medir la previsible dispersión en el tiempo de auxiliar para atender las necesidades en actividades de la vida diaria de un determinado perfil de residente. Aspiramos a definir un patrón de tiempos respecto a un baremo cuyos resultados se entienden aleatorios, pero con una dispersión medida y aceptada y que, además, contemple los efectos de posibles causas colaterales (conocimiento real del residente y alteraciones conductuales). Por tanto, no busquemos complicar más un problema en sí complejo con consideraciones lícitas, pero con un efecto sobre los resultados presumiblemente despreciable. ¿Por qué prejuzgar que los medidores pueden llegar a sesgar el resultado por malas praxis en la medición cuando no hay que ajustarse a criterios subjetivos? Estamos midiendo tiempos con un medio técnico calibrado (cronómetro) y conforme a unas reglas concretas. Es muy improbable que, bajo las mismas condiciones de observación, dos medidores distintos lleguen a resultados significativamente diferentes.

\subsubsection{Situación cambiante del residente y del auxiliar de geriatría}

Hemos contemplado la posibilidad de cambios a medio plazo en el grupo de dependencia según la valoración Barthel. Si eliminamos las colas de la distribución de frecuencias de puntuaciones Barthel según los datos facilitados por una de las organizaciones objeto de estudio, el plazo medio de cambio se sitúa en 350 días, con una desviación estándar de 232 días. Estos estadísticos descriptivos parecen indicar que el estado asistencial del residente permanece invariable, por término medio, durante un año. Una medida que, sin embargo, no podemos extrapolar, porque no ha sido sometida a correlación con variables como la edad del residente o su estado de salud. Si bien este horizonte temporal puede constituirse en referencia para asociaciones válidas entre BVD y Barthel (a falta de una, la otra puede ser un buen sustitutivo si no se alejan más de un año en el tiempo), no sería aconsejable dilatar las mediciones repetidas para un mismo residente a diferentes momentos en un periodo de un año natural, porque, con toda probabilidad, habrá cambiado su perfil y, en un porcentaje no despreciable de casos , se producirán bajas debidas a la altísima edad media de la población atendida.
Empíricamente constatamos que el tiempo de apoyo de tercera persona requerido por un mismo residente con una situación estable no es constante. Así lo certifican las opiniones vertidas por los profesionales de atención directa de las organizaciones participantes en este estudio. No sólo presumimos que una misma puntuación Barthel no tiene por qué corresponderse ineludiblemente con un tiempo estándar, sino que, además, una misma persona tampoco tiene por qué mantenerse invariable en el tiempo, ni tan siquiera a corto plazo. Aun siendo conscientes de la premisa, la escasa o nula información empírica con la que trabajar dificulta la definición de un número adecuado de repeticiones de medición en un mismo sujeto para determinar hasta qué punto el resultado depende del estado integral del residente (factores endógenos) 0 de la actitud/aptitud del profesional que lo atiende (factores exógenos).

En cualquier caso, la situación cambiante del residente por factores endógenos no es sino un caso particular de la hipótesis sobre la que gira todo nuestro estudio: dos residentes con una idéntica configuración de perfil Barthel pueden presentar resultados diferentes en términos de tiempo de auxiliar. La cuestión es medir la dispersión y tratar de encontrar patrones (intervalos) conforme a técnicas estadísticas. Dada la composición aleatoria de la prestación del servicio, en principio no cabría distinguir entre la casuística presentada por dos perfiles absolutamente idénticos en un mismo momento y la de un mismo perfil en dos momentos distintos.

La selección de los elementos de la muestra sigue un sistema de búsqueda aleatoria. Es de esperar que los profesionales que realicen su labor durante las mediciones también se vayan sucediendo de manera aleatoria. En consecuencia, la muestra contemplará tiempos sesgados por efecto de factores endógenos (alteraciones conductuales, estado de ánimo, proactividad, apatía) y exógenos (actitud/aptitud del profesional). Al trabajar con un margen de error muestral del $3 \%\left(\bar{x}-2,17 \sigma_{\bar{x}} \leq \mu_{\bar{x}} \leq \bar{x}+2,17 \sigma_{\bar{x}}\right)$, entendemos que el efecto producido por ambos tipos de factores ya está implícitamente contemplado en el propio intervalo de confianza. En cualquier caso, el registro para la toma de tiempos detallará la intensidad de los factores endógenos y exógenos para, llegado el caso, poder analizar por separado las posibles correlaciones entre los tiempos observados y la referida intensidad.

Según vayamos avanzando en la planificación del proyecto (véase el apartado 3.3.), el acopio de datos contrastados y fidedignos nos permitirá conjugar las dos variables que, a priori, pueden explicar la dispersión esperada de tiempos de auxiliar: la experiencia laboral, traducida en términos de conocimiento real del residente (saber hacer de cada centro), y las alteraciones conductuales de los residentes. En cualquier caso, este análisis no deber ser ignorado, porque podría estar detrás del incumplimiento de los intervalos de tolerancia definidos para cada ítem del Barthel. Este punto es especialmente interesante, porque en buena parte revelaría las causas que 
explican los resultados negativos obtenidos en las distintas supervisiones.

\subsubsection{Programación de mediciones en el tiempo}

El tiempo que se asigne a la labor de campo condicionará el ritmo diario de mediciones y, en consecuencia, el número necesario de medidores para completar la toma de datos. Si consideramos que, en dos meses, pueden cerrarse las mediciones, ello supondría realizar 17 diarias, que habría que repartir proporcionalmente al tamaño de cada centro. Desde luego, no sería económicamente viable que cada medidor 'persiguiera' al residente que se desea medir durante 24 horas para asignar tiempos a cada combinación componente-módulo (supondría contar 51 medidores diarios, a razón de 8 horas de observación por cada uno de ellos). ¿Cómo podemos organizar la medición, disponiendo de un único medidor en cada centro, sin dilatar en exceso el proceso, ni asumir un coste innecesario?

La prestación de servicios residenciales debe caracterizarse por desarrollarse en el entorno de una actividad organizada y programada. Los hábitos diarios de las personas mayores que conviven en un centro residencial no se distinguen especialmente de los usos y costumbres del resto de la sociedad. Todos sin excepción nos levantamos, realizamos una actividad, nos alimentamos, nos desplazamos, descansamos, nos aseamos y atendemos a nuestras necesidades fisiológicas de modo más o menos autónomo. Además, lo hacemos conforme a unas rutinas y frecuencias a lo largo del día que, en la práctica totalidad de los casos, repiten un patrón básicamente común. Este hecho nos sugiere que muchos componentes se repiten con determinada frecuencia a lo largo del día y, por tanto, podría ser suficiente una medición para obtener el tiempo total (producto de dicha medición por la frecuencia en la que se presenta un componente). Si bien es cierta esta observación, no lo es menos que no todos los componentes pueden ser aislados para la toma de tiempos, ni que el trabajo de una gerocultora se realiza bajo unas mismas condiciones, incluso físicas o ambientales.

Así, determinados componentes son independientes de la distribución arquitectónica del geriátrico, mientras que otros dependen absolutamente de la ubicación de las distintas dependencias. Las tareas implícitas en módulos como 'alimentación', 'control de esfínteres', 'higiene personal', 'acicalamiento', 'vestirse' y 'transferencias' seguirán una secuencia similar en todos los centros; por su parte, la necesidad de ayuda medida como tiempo para el módulo 'desplazamiento' estará supeditada a la separación física entre las distintas zonas o dependencias del inmueble. Dos variables determinarán el tiempo necesario para desplazar a los residentes por el centro: la distancia horizontal o a un mismo nivel entre dos puntos del centro, $y$ la distancia vertical o a distinto nivel entre ambos puntos. La primera depen- derá de la velocidad de desplazamiento; la segunda, del número y la capacidad de los medios mecánicos para salvar las barreras arquitectónicas (ascensores, plataformas, elevadores). Por todo ello, definir con el mayor detalle posible el programa de tareas de las auxiliares a lo largo del día se muestra como la piedra de clave sobre la que sustentar nuestra construcción. Desde este programa, detectaremos la frecuencia de las tareas y las necesidades de desplazamiento, de modo que, tomando mediciones en los intervalos del día con presencia del mayor número de módulos y componentes, podamos estimar tiempos diarios totales con suficiente aproximación.

Siguiendo con nuestro modelo de programación de tareas, veamos ahora con qué frecuencia se repiten qué tareas entre las 8:00 y las 22:00 horas. En la Tabla 6-a, se detallan las tareas definidas en ese horario, identificándose la frecuencia en que se dan y el componente asociado; asimismo, en la Tabla 6-b se cuantifica el número de tareas distintas implícitas en los intervalos en los que se ha dividido la atención diurna.

Para la ejecución de las tareas programadas, las necesidades de horas de atención no se distribuyen de manera constante. En determinados intervalos del día, repunta la presencia de auxiliares, que se sitúa en mínimos en otros momentos. Estos 'picos' y 'valles' quedan de manifiesto en el Gráfico 2, que refleja la situación de una de las organizaciones que participan en este estudio.

Como se observa, prácticamente un $80 \%$ de las tareas están presentes desde el momento de levantarse hasta la hora de comer o, lo que es lo mismo, entre las 8:00 y las 14:00 horas. Recordemos la normalidad de este dato si consideramos que la vida en un geriátrico no es ajena a las prácticas domésticas de cualquier vivienda particular (salvo en las relaciones proactivas con el exterior, un residente necesita cubrir idénticas necesidades que cualquier otro adulto). A nada que añadamos las tareas específicas fuera del intervalo, con controlar una parte del día podríamos extrapolar datos al resto de la jornada por efecto de la frecuencia. Si consideramos que comer/ cenar y levantar/acostar son tareas similares, sintetizaríamos aún más la toma de datos. En definitiva, si dispusiéramos de los siguientes recursos, abarcaríamos la medición de todas las tareas implícitas en un día de atención:

- Un medidor externo entre las 8:00 y las 12:30.

- Un medidor interno (enfermero/a, auxiliar referencial o similar) para medir el tiempo de las tareas 'comer', 'merendar' e ‘hidratación oral'.

Para un tamaño de muestra como el propuesto (793 elementos) y un plazo de dos meses, el número de mediciones diarias por centro y día, distribuidas proporcionalmente al tamaño de cada entidad, quedaría tal como expresa la Tabla 7. 
Tabla 6a. Tareas y frecuencias, por componente

\begin{tabular}{|c|c|c|}
\hline Tarea & Componente & $f_{i}$ \\
\hline Acostar & Acostar & 1 \\
\hline Afeitado (hombre) & Acicalamiento & 1 \\
\hline Cenar & Cena & 1 \\
\hline Comer & Comida & 1 \\
\hline \multirow{2}{*}{ Comprobación estado pañal } & Cambio pañal diurno encamados & 1 \\
\hline & WC & 1 \\
\hline Desayunar & Desayuno & 1 \\
\hline \multirow{6}{*}{ Desplazamiento } & Habitación .... WC & 1 \\
\hline & Origen $\ldots . .>$ actividades & 3 \\
\hline & Origen...$>$ comedor & 2 \\
\hline & Origen ..... habitación & 5 \\
\hline & Origen...$>$ salones & 2 \\
\hline & Origen $\ldots .>$ WC (según frecuencia) & 2 \\
\hline \multirow{2}{*}{ Desvestir } & Vestirse & 2 \\
\hline & WC & 1 \\
\hline Ducha/baño (aseo personal) & Ducha/baño & 1 \\
\hline Ejecutar pautas de pizarras & Pautas de pizarras & 1 \\
\hline Hidratación oral & Merienda & 2 \\
\hline Levantar del WC & WC & 3 \\
\hline Limpieza bucal & Higiene bucal & 1 \\
\hline Merendar & Merienda & 2 \\
\hline Paseos/bipedestaciones & Ejercicios bipedestación/paseos & 1 \\
\hline Secar e hidratar & Ducha/baño & 1 \\
\hline Sentar en WC & WC & 2 \\
\hline \multirow{4}{*}{ Transferencia } & Ejercicios bipedestación/paseos & 4 \\
\hline & Origen .... cama & 1 \\
\hline & Origen...$>$ silla & 5 \\
\hline & Origen .... sillón & 1 \\
\hline \multirow{2}{*}{ Vestir } & Vestirse & 1 \\
\hline & WC & 1 \\
\hline WC & WC & 2 \\
\hline
\end{tabular}

* Tareas no presentes en el intervalo 8:00-12:30: comer, merendar, hidratación oral, cenar y acostar.

Fuente: Elaboración propia.
Tabla 6b. Tareas por intervalo*

\begin{tabular}{|l|c|}
\hline Intervalo & No tareas \\
\hline 8:00-10:30 & 11 \\
\hline 10:30-12:30 & 4 \\
\hline 12:30-14:00 & 1 \\
\hline 14:00-16:30 & 2 \\
\hline 16:30-18:30 & 0 \\
\hline 18:30-19:30 & 0 \\
\hline 19:30-20:30 & 0 \\
\hline $20: 30-22: 00$ & 1 \\
\hline Total & 19 \\
\hline
\end{tabular}

\section{Gráfico 2. Distribución del número de auxiliares, por intervalos horarios}

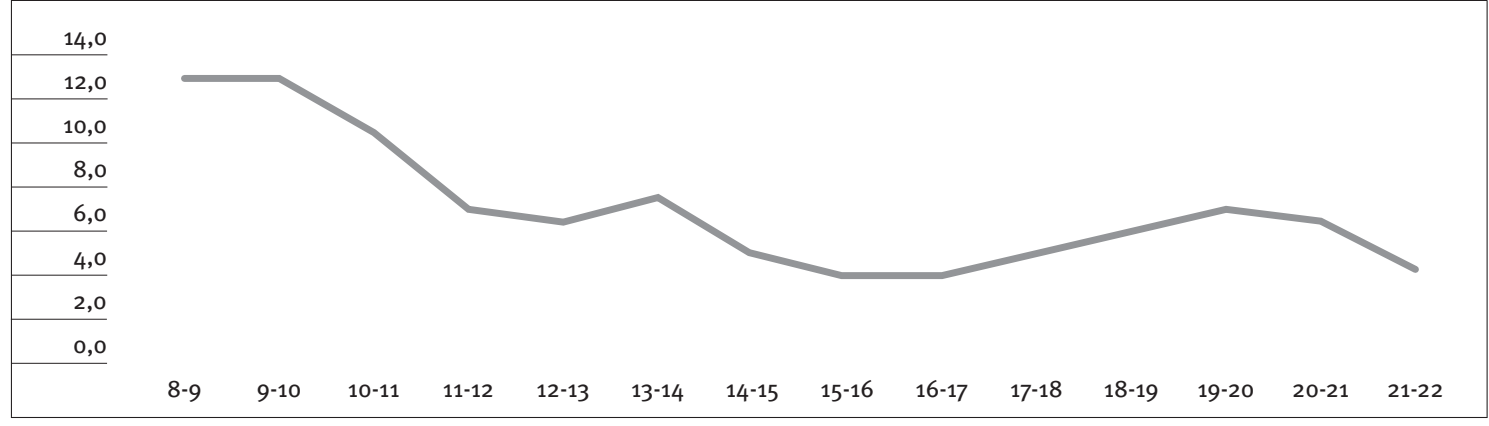

Fuente: Centro de Lares Euskadi.

Tabla 7. Determinación de la muestra diaria

\begin{tabular}{|c|c|c|}
\hline Centro & Tamaño & Muestra diaria \\
\hline Nuestra Sra. de la Paz & 75 & 1 \\
\hline Fundación Zorroaga & 300 & 3 \\
\hline Santa y Real Casa de Misericordia Bilbao & 215 & 2 \\
\hline Fundación Aspaldiko & 280 & 2 \\
\hline Fundación Miranda & 229 & 2 \\
\hline Aita Menni & 341 & 3 \\
\hline Santa y Real Casa de Misericordia Pamplona & 585 & 4 \\
\hline Total de plazas & 2.025 & 17 \\
\hline
\end{tabular}

* Por tamaño, la Santa y Real Casa de Misericordia de Pamplona contaría con dos medidores para realizar las cuatro mediciones diarias.

Fuente: Elaboración propia. 
Sin embargo, aún no hemos resuelto el problema. Si bien las tareas se suceden secuencialmente según el programa definido, unas veces se ejecutan de forma individual ('ducha/baño', 'transferencia' o 'comprobación estado de pañal') y otras de modo grupal (algunos tipos de 'desplazamientos' o supervisión de salones en momentos concretos del día). ¿Cómo posibilitar la medición de tiempos cuando teóricamente varios de los residentes de la muestra pueden estar atendidos a la vez? Dado que no tenemos el don de la ubicuidad, organizaremos la atención a los residentes seleccionados de tal manera que se conviertan en actos separados. No hay otra alternativa si no queremos incurrir en un incremento de costes por necesidad de un número mayor de medidores. Si fuera necesario, retrasaríamos o adelantaríamos determinadas tareas para aislar la atención de los residentes seleccionados para cada día y permitir la presencia del medidor para atestiguar la toma de datos. Dado que limitaremos a tres las mediciones diarias, se entiende asumible el ajuste organizativo de procurar dicha presencia.

\subsubsection{Tareas repetidas de duración constante}

Ya hemos adelantado que muchas de las tareas se repiten a lo largo de un día de atención. Por ello, carece de sentido la toma de tiempos para cada una de las repeticiones, en la medida que no aportan valor más allá de incrementar una dispersión ya existente. Si la atención se presta bajo idénticas condiciones, se entiende suficiente medir una cualquiera de las tareas semejantes o equivalentes para definir el valor que las representa. Así, sobre el programa diario de atención, detectadas las tareas 'homogéneas', una vez consensuadas por el grupo de trabajo, obtenemos la clasificación de la Tabla 8.

Tabla 8. Tareas repetidas de duración constante

\begin{tabular}{|c|c|c|}
\hline Tarea & $f_{i}$ & Componente afectado \\
\hline \multirow{2}{*}{ Comer } & \multirow{2}{*}{2} & Cena \\
\hline & & Comida \\
\hline \multirow{2}{*}{$\begin{array}{l}\text { Comprobación } \\
\text { estado pañal }\end{array}$} & \multirow{2}{*}{2} & Cambio pañal diurno encamados \\
\hline & & WC \\
\hline \multirow{2}{*}{ Desvestir } & \multirow{2}{*}{4} & Vestirse \\
\hline & & WC \\
\hline Levantar del WC & 2 & WC \\
\hline Limpieza bucal & 3 & Higiene bucal \\
\hline Sentar en el WC & 2 & WC \\
\hline \multirow{4}{*}{ Transferencia } & \multirow{4}{*}{13} & Ejercicios bipedestación/paseos \\
\hline & & Origen $\cdots>$ cama \\
\hline & & Origen $\cdots$ s silla \\
\hline & & Origen $\cdots$-.> sillón \\
\hline \multirow{2}{*}{ Vestir } & \multirow{2}{*}{2} & Vestirse \\
\hline & & WC \\
\hline WC & 2 & WC \\
\hline
\end{tabular}

Fuente: Elaboración propia.
El tiempo total diario será el resultado de multiplicar el tiempo medio asignado a la tarea para un nivel de confianza del $97 \%$ por el número de veces que es repetida (frecuencia).

\subsubsection{Tareas repetidas de duración variable}

Dos son las tareas que se interpretan como variables en su ejecución, o no realizables bajo unas circunstancias más o menos homogéneas: 'desplazamientos' y 'estimulación física'. A diferencia de las anteriores, hemos de definir qué variables intervienen en la ejecución de la tarea, pero intentando discriminar al máximo las que realmente tienen verdadera influencia sobre el resultado. Es evidente que el tiempo de desplazamiento por el centro depende de la distancia recorrida y del desnivel, así como de otros factores de menor incidencia (tipo de ayuda técnica, capacidad física del trabajador). Como para el resto de mediciones es fundamental distinguir cuándo la ayuda de tercera persona se presta en correspondencia biunívoca (ayuda total: un profesional = un tiempo, es decir, un profesional para atender a un residente) o no unívoca (supervisión: un profesional = varios tiempos, es decir, un profesional para $n$ residentes).

Interpretar la supervisión no es tarea fácil. Su consideración es diferente en caso de medir un componente como 'desplazamiento' o como 'vestir'. Para el primero, la supervisión se produce mientras se desarrolla la actividad (correspondencia no unívoca: vigilancia mientras varios residentes se desplazan autónomamente); para el segundo, la supervisión se realiza bien mientras se viste, bien a posteriori, mediante las oportunas comprobaciones del estado de la ropa o de la estética (correspondencia biunívoca). En cualquier caso, podríamos estar teorizando, porque, en definitiva, la posibilidad de aislar la medición está absolutamente condicionada por el modelo organizativo de cada centro.

La imposibilidad de ajustar las mediciones a la infinidad de casuísticas nos exige resolver el problema de una manera práctica, razonable y sintetizada (recordemos que hemos defendido cierto grado de osadía en la búsqueda de un patrón de funcionamiento). Por ello, relacionaremos ambos componentes ('desplazamiento' y 'estimulación física') con dos únicas variables: distancia y desnivel. Para ambas, en correspondencias no unívocas, dividiremos el tiempo de supervisión entre el total de residentes supervisados. El objetivo último es definir un parámetro (tiempo por metro recorrido) que permita cuantificar el tiempo total para los distintos recorridos por el centro.

\subsubsection{Auxiliar de noche}

La programación de la atención nocturna es consecuencia de un contexto asistencial que poco tiene que ver con las necesidades diurnas. Grosso modo, las tareas nocturnas pueden resumirse en 
las siguientes: cambios posturales, cambios de pañal, administración de medicación y recenas. Por supuesto, la atención de situaciones de urgencia es también responsabilidad de la auxiliar de noche, pero a diferencia de las anteriores, no está sujeta a programación alguna. En consecuencia, la asignación de ratios nocturnas no se plantea en idénticos términos, ni en metodología, que los diurnos. Dependerá de características como la distribución física del inmueble (en teoría, construcciones verticales requerirán de mayores tiempos de desplazamiento que construcciones horizontales), la concentración de determinados estados de salud (gripes, diarreas, vómitos) o las alteraciones conductuales en residentes con autonomía para deambular y sin restricciones físicas. Estas últimas, como demuestra el Gráfico 3, revisten especial importancia, porque se registran en un porcentaje con considerable peso específico, a pesar de la supuesta baja intensidad en la actividad del geriátrico.

Gráfico 3. Distribución de las alteraciones conductuales, por turno de trabajo

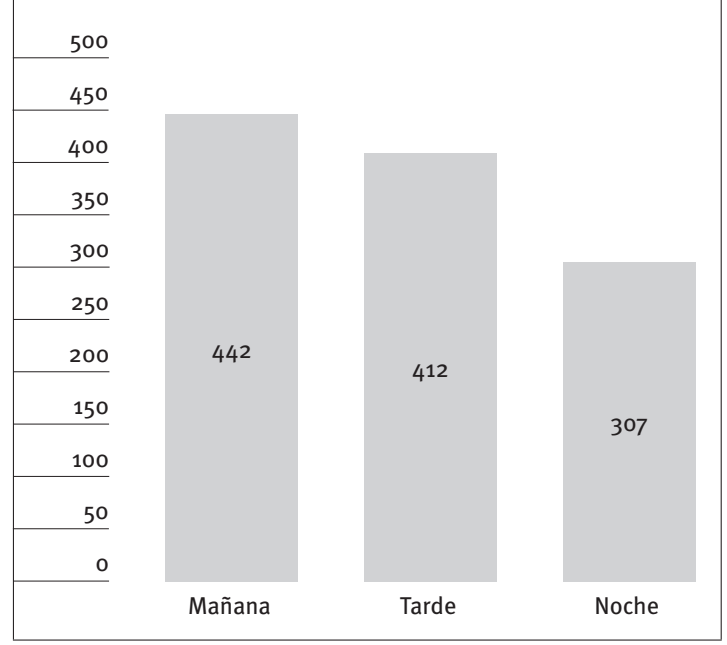

Fuente: Centro de Lares Euskadi.

En consecuencia, si aceptamos que el trabajo nocturno es más o menos constante durante la noche y que, salvo episodios, se mantiene en el tiempo, la asignación de auxiliares será principalmente un problema organizativo contextualizado en cada centro. En todo caso, el análisis comparativo de las distintas soluciones implantadas por el conjunto de organizaciones del sector podría constituir la base sobre la que asentar un modelo empírico de atención. Un ánimo difícil de llevar a cabo, porque la posibilidad de contar con fracciones de jornada en calendario nocturno es prácticamente inviable. Supongamos que, del estudio empírico, se deduce que la proporción adecuada de auxiliar de noche es de 1 a 40 (un trabajador por cada 40 residentes). Para otro centro que dispone de 50 plazas, la proporción computa en 1,25 la necesidad de auxiliar nocturno. ¿Cómo fijamos su horario: un $25 \%$ de los días a jornada completa o la totalidad de sus días laborales a un $25 \%$ de jor- nada? El patrón podría ser válido, pero sólo a efectos de comparación entre centros. La regla es, precisamente, que no hay regla.

\subsubsection{Selección de elementos de la muestra}

Recordemos que, a falta de mayor conocimiento de los parámetros de la población y de los estratos que la componen (en ningún caso conocemos la media [m], ni la desviación típica [s]) hemos optado por maximizar el tamaño de la muestra (valor tipificado de la desviación igual a 0,5) y estratificar los grupos de dependencia proporcionalmente a su tamaño en la población. Ello obliga a conocer cuántos residentes tienen una valoración Barthel de entre o y 79 puntos (grandes dependientes), de entre 80 y 99 (dependientes) y de 100 (autónomos). Una vez conocida la proporción de cada grupo sobre la población, dividiremos cada estrato para cada centro en proporción, también, al tamaño de cada grupo respecto al total (véase la Tabla 9).

Obvia decir que la selección de residentes debe ser aleatoria y asegurar, además, que todos tengan la misma probabilidad de integrar la muestra (elementos equiprobables). En consecuencia, huiremos de criterios como elegir residentes secuenciales entre los que tienen valoración independientemente de la antigüedad de ésta, o a aquéllos cuyo apellidos empiecen por las letras A, D, G y P hasta completar el tamaño del estrato. Se rechazará cualquier condición que mediatice la selección de elementos si no queremos que los datos puedan presentar sesgos.

El muestreo, por otra parte, debe producirse sin reemplazamiento. Es aconsejable que un mismo residente no sea nuevamente seleccionado, no por cumplimiento de ninguna ley estadística, sino por maximizar la variabilidad de perfiles dentro de cada grupo o estrato. Porque, si como ya se ha indicado, un residente es, en sí mismo, aleatorio (recordemos el hipotético sesgo de los factores endógenos y exógenos en la prestación del servicio), no habría mayor inconveniente en que formara parte de muestra de manera sucesiva. No obstante, como dichos factores no se manifiestan permanentemente, cabría la posibilidad de medir a un mismo residente dos o más veces para obtener un resultado probablemente similar, y es fundamental ampliar la casuística para abarcar la máxima dispersión posible en la definición de un patrón de funcionamiento.

En una aplicación de Excel, iremos asignando valores equiprobables dentro del intervalo (0-1) para la selección aleatoria de residentes. Intervendremos en la búsqueda para evitar repeticiones y limitar el número de elementos por estrato al tamaño previamente definido para cada uno de ellos en cada centro. Mediante los oportunos controles, validaremos la selección $\mathrm{y}$, en caso contrario, repetiremos el proceso hasta cumplir con las condiciones requeridas. Dado que no es objeto del presente trabajo la explicación detallada de la programación informática implícita en la 
Tabla 9. Simulación de los elementos de la muestra

\begin{tabular}{|c|c|c|c|c|c|c|c|c|}
\hline \multicolumn{4}{|c|}{ Residente } & \multicolumn{5}{|c|}{ Búsqueda aleatoria } \\
\hline \multirow{2}{*}{ № } & \multirow{2}{*}{ Nombre } & \multirow{2}{*}{ Barthel } & \multirow{2}{*}{ Grupo } & \multirow{2}{*}{$\begin{array}{c}\text { № } \\
\text { aleatorio }\end{array}$} & \multirow{2}{*}{ Residente } & \multicolumn{3}{|c|}{ Muestra y estratos } \\
\hline & & & & & & A & D & GD \\
\hline 1 & Residente Zorroaga-1 & 88 & D & 232 & Residente Zorroaga-232 & 0 & 1 & 0 \\
\hline 2 & Residente Zorroaga-2 & 10 & GD & 191 & Residente Zorroaga-191 & 0 & 0 & 1 \\
\hline 3 & Residente Zorroaga-3 & 100 & A & 29 & Residente Zorroaga-29 & 1 & 0 & 0 \\
\hline 4 & Residente Zorroaga-4 & 5 & GD & 131 & Residente Zorroaga-131 & 0 & 0 & 2 \\
\hline 5 & Residente Zorroaga-5 & 32 & GD & 292 & Residente Zorroaga-292 & 0 & 0 & 3 \\
\hline 6 & Residente Zorroaga-6 & 38 & GD & 245 & Residente Zorroaga-245 & 0 & 0 & 4 \\
\hline$[\ldots]$ & {$[\ldots]$} & {$[\ldots]$} & {$[\ldots]$} & {$[\ldots]$} & {$[\ldots]$} & {$[\ldots]$} & {$[\ldots]$} & {$[\ldots]$} \\
\hline 128 & Residente Zorroaga-128 & 17 & GD & 132 & & 0 & 0 & 0 \\
\hline 129 & Residente Zorroaga-129 & 100 & A & 245 & Residente Zorroaga-245 & 15 & 0 & 0 \\
\hline 130 & Residente Zorroaga-130 & 38 & GD & 208 & & 0 & 0 & 0 \\
\hline$[\ldots]$ & {$[\ldots]$} & {$[\ldots]$} & {$[\ldots]$} & {$[\ldots]$} & {$[\ldots]$} & {$[\ldots]$} & {$[\ldots]$} & {$[\ldots]$} \\
\hline 184 & Residente Zorroaga-184 & 94 & D & 168 & Residente Zorroaga-168 & 0 & 39 & 0 \\
\hline 185 & Residente Zorroaga-185 & 74 & GD & 299 & & 0 & 0 & 0 \\
\hline 186 & Residente Zorroaga-186 & 95 & D & 162 & & 0 & 0 & 0 \\
\hline & & & & & Total & 22 & 39 & 86 \\
\hline
\end{tabular}

A: autónomo. D: dependiente. GD: gran dependiente.

Fuente: Elaboración propia.

\section{Figura 1. Programación diaria de mediciones}

\begin{tabular}{|l|l|l|l|}
\hline 2015 & Muestra por selección equiprobable & Inicio de mediciones & 1-2-15 \\
\cline { 3 - 4 } & & Fin de mediciones & 30-3-15 \\
\hline
\end{tabular}

\begin{tabular}{|l|l|}
\hline Entidad & $\begin{array}{l}\text { Fundación } \\
\text { Zorroaga }\end{array}$ \\
\hline $\begin{array}{l}\text { № mediciones } \\
\text { diarias }\end{array}$ & 3 \\
\hline
\end{tabular}

\begin{tabular}{|l|c|c|c|c|}
\hline Concepto & \multicolumn{4}{|c|}{ Muestra válida } \\
\hline Grupo & A & D & GD & $n$ \\
\hline$n$ teórico & 22 & 39 & 86 & 147 \\
\hline$n$ listado & 22 & 39 & 86 & \\
\hline
\end{tabular}

\begin{tabular}{|c|c|c|c|c|c|}
\hline Fecha & Grupo & Nombre & Cód. & Barthel & Total \\
\hline \multirow{4}{*}{$2 / 2 / 2015$} & A & Residente Zorroaga-5 & 5 & 100 & 1 \\
\hline & $\mathrm{D}$ & Residente Zorroaga-247 & 247 & 88 & 1 \\
\hline & GD & Residente Zorroaga-292 & 292 & 10 & 1 \\
\hline & \multicolumn{4}{|l|}{ Total } & 3 \\
\hline \multirow{4}{*}{$03 / 2 / 2015$} & \multirow{3}{*}{ GD } & Residente Zorroaga-112 & 112 & 5 & 1 \\
\hline & & Residente Zorroaga-224 & 224 & 38 & 1 \\
\hline & & Residente Zorroaga-87 & 87 & 32 & 1 \\
\hline & \multicolumn{4}{|l|}{ Total } & 3 \\
\hline \multicolumn{6}{|l|}{$[\ldots]$} \\
\hline \multirow{4}{*}{$30 / 3 / 2015$} & \multirow{3}{*}{ D } & Residente Zorroaga-215 & 215 & 94 & 1 \\
\hline & & Residente Zorroaga-82 & 82 & 96 & 1 \\
\hline & & Residente Zorroaga-96 & 96 & 85 & 1 \\
\hline & \multicolumn{4}{|l|}{ Total } & 3 \\
\hline
\end{tabular}


extracción de la muestra, ilustraremos los resultados a través de las Tabla 9 y la Figura 1 para un centro con capacidad para 300 residentes (Fundación Zorroaga).

Toda vez que hayamos determinado qué residentes conforman la muestra de 147 elementos (22 autónomos, 39 dependientes y 86 grandes dependientes), distribuiremos la medición de tiempos para un plazo previsto de dos meses (se entiende que las mediciones se desarrollarán de lunes a sábado). Como una resultante más de la aplicación, obtendremos un registro que aleatoriamente irá relacionando residentes para cada día hasta completar la muestra. Lógicamente, el periodo de mediciones no debería desviarse sustancialmente del plazo acordado. En concreto, para el centro en cuestión, la programación quedaría como expresa la Figura 1.

\subsubsection{Garantía de presencia suficiente de todo tipo de perfiles en la definición de isogrupos}

Entendemos por isogrupo aquel grupo de residentes que reciben un mismo intervalo de tiempo de auxiliar. Para que el sistema sea operativo interna (cada geriátrico) y externamente (administración pública), no podemos plantear el abordaje de todas y cada una de las posibles combinaciones que pudieran salir de la administración del índice Barthel, habida cuenta la elevada cantidad de perfiles resultantes de conjugar los distintos itinerarios que puede recorrer una persona (10 ítems con 2 de 4 niveles de intensidad, 6 de 3 y 2 de 2). A nadie en su sano juicio se le ocurre trabajar con este abanico y, mucho menos, plantear algo ni parecido en la Administración. La idea de isogrupo pretende clasificar a los residentes por grupos homogéneos de consumo independientemente de su recorrido (distintos pasos por las combinaciones módulo - nivel de dependencia).

La posibilidad de agrupar las diferentes combinaciones de perfiles en conjuntos más o menos homogéneos no debería ser ajena a los costes asociados a cada grupo y, en consecuencia, a la financiación de dichos costes. Los isogrupos pueden definirse conforme a diferentes criterios, pero, en todo caso, sería aconsejable que tuvieran referencia como normas de ámbito comunitario o estatal, con la ambición de trascender ámbitos locales o, al menos, muy focalizados, para llegar a constituirse en un marco de comparación interterritorial (CAPV) o intercomunitaria (el Estado en su conjunto). Por ello, a pesar de las discrepancias que pudieran suscitarse al respecto, proponer la propia distribución considerada por el Decreto 174/2011 para “determinar el grado y nivel oficial de la dependencia” ayudaría a clasificar e identificar grupos con un consumo similar de tiempos.

No obstante, una hipótesis como la presentada debería ser cotejada con los datos obtenidos en la labor de campo. Pudiera ocurrir que los tiempos de paso para cada combinación de módulo y nivel de dependencia (CIF-OMS) arrojara unos totales ciertamente dispersos para cada isogrupo definido; incluso, que combina- ciones de grupos teóricamente más dependientes tuvieran tiempos menores que grupos con nivel de dependencia inferior, o viceversa. Para comprobar el cumplimiento o no de estas circunstancias, la muestra debe contener un número estadísticamente significativo de niveles de dependencia para cada módulo. En otras palabras, la muestra estará compuesta por al menos 50 observaciones ( $N$ mínimo para validaciones con el estadístico $\mathrm{C}^{2}$ ) para cada combinación de módulo y nivel de dependencia, de manera que podamos probar que existe asociación entre el tiempo de auxiliar y el isogrupo predefinido. No cumplir la hipótesis obligaría a redefinir isogrupos sin atender a ninguna clasificación oficial previa y, por tanto, a contextualizar la resolución del problema, cuando precisamente buscamos el efecto contrario.

\subsubsection{Proceso de medición}

Sólo cinco componentes no están presentes en el intervalo que va de las 8:00 a las 12:30 horas (comer, merendar, hidratación oral, cenar y acostar). Asociando comida a cena y acostar a levantar, bastaría con realizar tres mediciones (comer, merendar e hidratación oral) para completar el abanico de componentes. Evidentemente, cambios en el programa de tareas podrían suponer la medición de nuevos componentes.

Si buscamos minimizar el coste económico de la toma de tiempos, estamos condenados a ajustar la organización diaria para 'aislar' a los residentes que componen la muestra (en el caso que nos ocupa, residentes 5, 247 y 292 para el día 2/2/2015). Es básico que el medidor esté presente en la medición, para evitar sesgos malintencionados que pudieran contaminar el dato. Pero si algo es fundamental para asegurar la bondad de la medición, es acompañarla del mayor detalle descriptivo posible para contextualizar la prestación del servicio. Así, explicitaremos todo tipo de datos subordinados que se entiendan necesarios para concretar la casuística de la medición. Los ejemplos del Cuadro 6 intentan explicar a qué datos subordinados nos referimos.

\begin{tabular}{|c|c|}
\hline \multicolumn{2}{|c|}{$\begin{array}{l}\text { Cuadro 6. Ejemplo de datos subordinados necesarios para } \\
\text { concretar la casuística de la medición }\end{array}$} \\
\hline Tarea & Datos implícitos \\
\hline $\begin{array}{l}\text { Desplazamiento de } \\
\text { salón de actividades a } \\
\text { comedor }\end{array}$ & $\begin{array}{l}\text { - Distancia recorrida, tanto horizontal } \\
\text { como verticalmente (en metros). } \\
\text { - Número de elementos mecánicos eleva- } \\
\text { dores y capacidad. } \\
\text { - Modo de tracción: residente en silla } \\
\text { dependiente/autónomo, residente } \\
\text { autónomo con orientación/desorienta- } \\
\text { ción; residente con andador, pero con } \\
\text { supervisión. }\end{array}$ \\
\hline Comida & $\begin{array}{l}\text { - En boca, con sonda, supervisión, } \\
\text { autónomo. } \\
\text { - Alteraciones conductuales y causa que } \\
\text { las motiva. } \\
\text { - Estado de ánimo: apático, hiperactivo, } \\
\text { colaborador, disconforme. } \\
\text { - Indicar si está encamado o tiene } \\
\text { recena. }\end{array}$ \\
\hline
\end{tabular}

Fuente: Elaboración propia. 
Naturalmente, con la valoración complementaria a los propios ítems del Barthel y los niveles de gravedad propuestos por la CIF-OMS, ya estamos determinando la dependencia real de una persona en términos de necesidad de ayuda de tercera persona. Si hubiera un artilugio técnico o mecánico que supliera dicha necesidad, no habría tercera persona $y$, en consecuencia, el tiempo asociado se correspondería estrictamente con la colocación, programación y control del instrumento. En consecuencia, hay que ser sumamente exquisito y consecuente cuando evaluemos el porcentaje de dependencia o necesidad de ayuda (técnica o personal) para la realización de una actividad. Por todo ello, la persona encargada de medir el tiempo empleado en la ejecución de los componentes debería ser un profesional con experiencia suficiente y contrastada, perfectamente conocedor de lo que hay detrás de la atención residencial de la persona mayor.

¿Cómo afecta la frecuencia en la que se repiten determinadas tareas a la toma de tiempos? Distinguiremos dos tipos de frecuencias: aquellas en las que la tarea se produce prácticamente bajo unas misma condiciones y aquellas otras en las que las condiciones varían. Si bien a las primeras pudieran afectarles factores endógenos del residente, en condiciones normales clasificaríamos las tareas repetidas conforme a lo recogido en la Tabla 10.
Tabla 10. Tareas repetidas, según duración

\begin{tabular}{|c|c|c|c|}
\hline Duración & Tarea & Componente & $f_{i}$ \\
\hline \multirow{6}{*}{ Fija } & \multirow{2}{*}{ Comer } & Cena & 1 \\
\hline & & Comida & 1 \\
\hline & \multirow{4}{*}{ Transferencia } & $\begin{array}{l}\text { Ejercicios bipedestación/ } \\
\text { paseos }\end{array}$ & 2 \\
\hline & & Origen...$>$ cama & 1 \\
\hline & & Origen $\cdots . . .>$ silla & 5 \\
\hline & & Origen $\cdots$..> sillón & 1 \\
\hline \multirow{6}{*}{ Variable } & \multirow{6}{*}{ Desplazamiento } & Habitación $\ldots . .>$ WC & 1 \\
\hline & & Origen $\cdots \rightarrow$ actividades & 1 \\
\hline & & Origen $\cdots>$ comedor & 2 \\
\hline & & Origen $\cdots . .>$ habitación & 2 \\
\hline & & Origen $\ldots . .>$ salones & 4 \\
\hline & & $\begin{array}{l}\text { Origen .... WC (según } \\
\text { frecuencia) }\end{array}$ & 2 \\
\hline
\end{tabular}

Fuente: Elaboración propia.

El medidor dispondrá de un perfil del residente que vaya a medir (Barthel con descripción detallada de su nivel de dependencia) [Figura 2] y de un registro de chequeo de medición (Figura 3). Este último documento contará con la información para concretar el perfil del residente, además de disponer, a pie de página, de una relación secuenciada de tareas, para comprobar su seguimiento.

Figura 2. Relación entre el índice Barthel (adaptado a gravedad*) y el Baremo de Valoración de la Dependencia

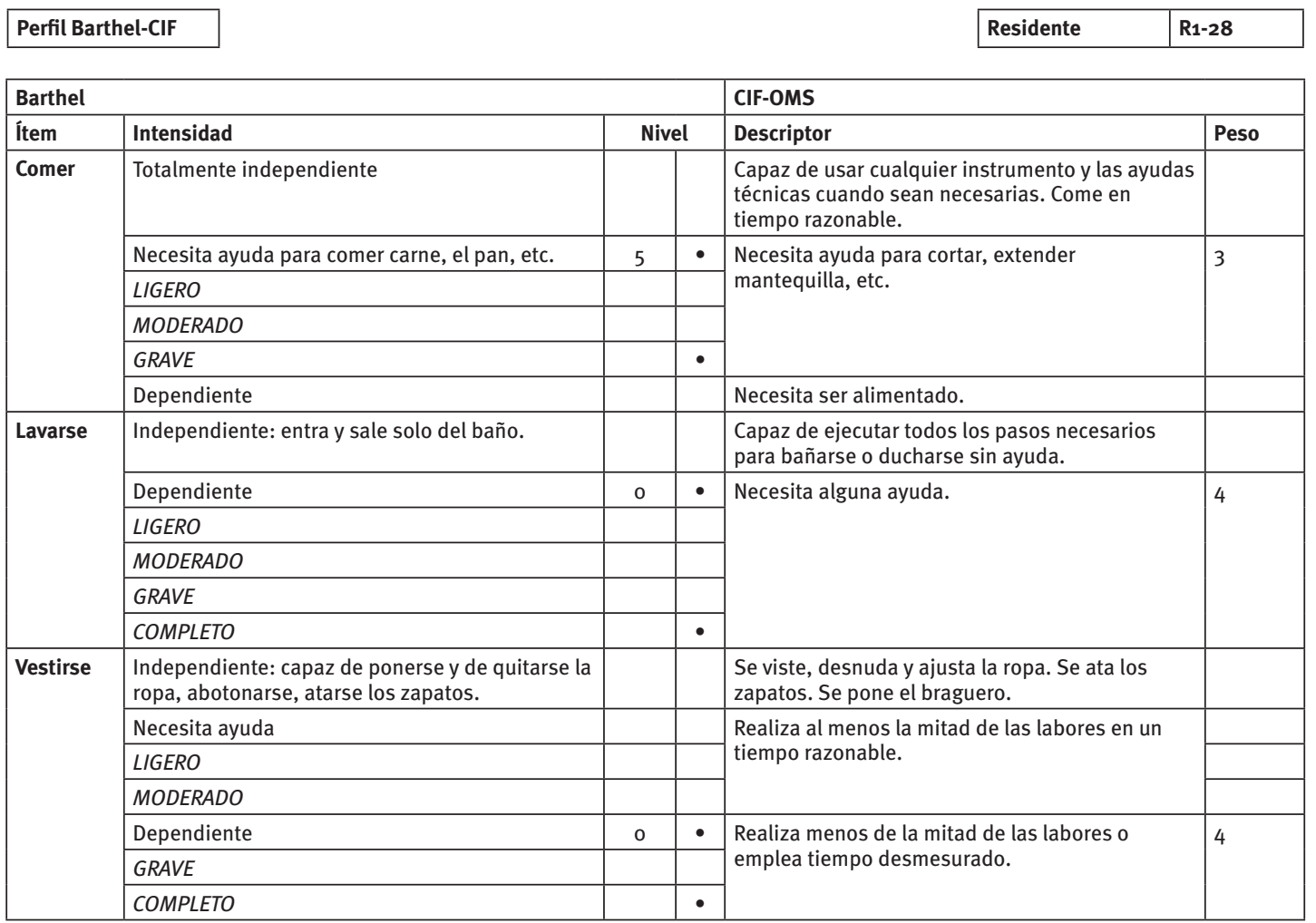




\begin{tabular}{|c|c|c|c|c|c|}
\hline \multicolumn{4}{|l|}{ Barthel } & \multicolumn{2}{|l|}{ CIF-OMS } \\
\hline Ítem & Intensidad & $\mathrm{Ni}$ & & Descriptor & Peso \\
\hline \multirow{6}{*}{ Arreglarse } & $\begin{array}{l}\text { Independiente para lavarse la cara, las manos, } \\
\text { peinarse, afeitarse, maquillarse, etc. }\end{array}$ & & & $\begin{array}{l}\text { Realiza todas las actividades personales: se } \\
\text { lava las manos y cara, los dientes, se afeita, } \\
\text { se maquilla, etc. }\end{array}$ & \\
\hline & Dependiente & 0 & $\bullet$ & \multirow{5}{*}{ Necesita alguna ayuda. } & \multirow{5}{*}{4} \\
\hline & LIGERO & & & & \\
\hline & MODERADO & & & & \\
\hline & GRAVE & & & & \\
\hline & COMPLETO & & $\bullet$ & & \\
\hline \multirow{7}{*}{ Deposiciones } & Continencia normal & 10 & $\bullet$ & No presenta episodios de incontinencia. & 0 \\
\hline & $\begin{array}{l}\text { Ocasionalmente algún episodio de incontinencia, } \\
\text { o necesita ayuda para administrarse supositorios o } \\
\text { lavativas. }\end{array}$ & & & \multirow[t]{3}{*}{ Episodios ocasionales de incontinencia. } & \\
\hline & LIGERO & & & & \\
\hline & MODERADO & & & & \\
\hline & Incontinencia & & & & \\
\hline & GRAVE & & & & \\
\hline & COMPLETO & & & & \\
\hline \multirow{7}{*}{ Micción } & $\begin{array}{l}\text { Continencia normal o capaz de cuidarse de la sonda si } \\
\text { tiene una puesta. }\end{array}$ & & & No presenta episodios de incontinencia. & \\
\hline & $\begin{array}{l}\text { Un episodio diario, como máximo, de incontinencia, o } \\
\text { necesita ayuda para cuidar de la sonda. }\end{array}$ & & & \multirow{3}{*}{ Episodios ocasionales de incontinencia. } & \\
\hline & LIGERO & & & & \\
\hline & MODERADO & & & & \\
\hline & Incontinencia & 0 & $\bullet$ & & \\
\hline & GRAVE & & & & 4 \\
\hline & COMPLETO & & $\bullet$ & & \\
\hline \multirow{7}{*}{ Usar el retrete } & $\begin{array}{l}\text { Independiente para ir al cuarto de aseo, quitarse y } \\
\text { ponerse la ropa, etc. }\end{array}$ & & & $\begin{array}{l}\text { Usa el retrete, bacinilla o cuña. Se sienta y } \\
\text { levanta, se limpia y viste. }\end{array}$ & \\
\hline & Necesita ayuda para ir al retrete, pero se limpia solo. & & & \multirow{3}{*}{$\begin{array}{l}\text { Necesita ayuda para mantener el equilibrio, } \\
\text { limpiarse o ponerse y quitarse la ropa. }\end{array}$} & \\
\hline & LIGERO & & & & \\
\hline & MODERADO & & & & \\
\hline & Dependiente & 0 & $\bullet$ & & \\
\hline & GRAVE & & & Incapaz de manejarse sin gran ayuda. & 4 \\
\hline & COMPLETO & & $\bullet$ & & \\
\hline \multirow{6}{*}{ Trasladarse } & Independiente para ir del sillón a la cama. & & & $\begin{array}{l}\text { No necesita ninguna ayuda. Si usa silla de } \\
\text { ruedas, es independiente. }\end{array}$ & \\
\hline & $\begin{array}{l}\text { Necesita una mínima ayuda física o supervisión para } \\
\text { hacerlo. }\end{array}$ & & & $\begin{array}{l}\text { Necesita supervisión verbal y pequeña } \\
\text { ayuda física. }\end{array}$ & \\
\hline & $\begin{array}{l}\text { Necesita gran ayuda, pero es capaz de mantenerse } \\
\text { sentado solo. }\end{array}$ & 5 & $\bullet$ & \multirow{3}{*}{$\begin{array}{l}\text { Capaz de sentarse, pero necesita mucha } \\
\text { asistencia para el traslado. }\end{array}$} & \multirow{3}{*}{3} \\
\hline & MODERADO & & & & \\
\hline & GRAVE & & $\bullet$ & & \\
\hline & Dependiente & & & $\begin{array}{l}\text { Incapaz de permanecer sentado. Necesita la } \\
\text { ayuda de dos personas en las trasferencias. }\end{array}$ & \\
\hline \multirow{11}{*}{ Deambular } & Independiente, camina solo 50 metros. & & & $\begin{array}{l}\text { Puede caminar independientemente al } \\
\text { menos } 50 \mathrm{~m} \text {, aunque se le ayude. }\end{array}$ & \\
\hline & $\begin{array}{l}\text { Necesita ayuda física o supervisión para caminar } 50 \\
\text { metros. }\end{array}$ & & & \multirow{4}{*}{$\begin{array}{l}\text { Puede caminar al menos } 50 \mathrm{~m} \text {, pero con } \\
\text { supervisión o ayuda. }\end{array}$} & \\
\hline & LIGERO & & & & \\
\hline & MODERADO & & & & \\
\hline & GRAVE & & & & \\
\hline & Independiente en silla de ruedas sin ayuda. & 5 & $\bullet$ & \multirow{5}{*}{ Propulsa su silla al menos $50 \mathrm{~m}$. } & 3 \\
\hline & INEXISTENTE & & & & \\
\hline & LIGERO & & & & \\
\hline & MODERADO & & & & \\
\hline & GRAVE & & $\bullet$ & & \\
\hline & Dependiente & & & Incluye ser desplazado por otro. & \\
\hline \multirow{6}{*}{ Escalones } & Independiente para subir o bajar escaleras. & & & $\begin{array}{l}\text { Capaz de subir y bajar escaleras sin ayuda } \\
\text { personal o supervisión. }\end{array}$ & \\
\hline & Necesita ayuda física o supervisión para hacerlo. & & & \multirow{4}{*}{ Necesita ayuda física o supervisión. } & \\
\hline & LIGERO & & & & \\
\hline & MODERADO & & & & \\
\hline & GRAVE & & & & \\
\hline & Dependiente & 0 & $\bullet$ & $\begin{array}{l}\text { Necesita alzamiento (ascensor) o no puede } \\
\text { salvar escalones. }\end{array}$ & 4 \\
\hline Total & & 25 & & Total & 33 \\
\hline
\end{tabular}

* De acuerdo a la Clasificación Internacional del Funcionamiento, de la Discapacidad y de la Salud (OMS).

Fuente: Elaboración propia a partir de datos del índice Barthel, del nivel de gravedad de las CIF y de los descriptores del BVD (Real Decreto 174/2011). 
Figura 3. Registro de tiempos de auxiliar de geriatría

\begin{tabular}{|c|c|c|c|c|c|c|c|c|c|}
\hline Levantarse - ini & io de actividad & tinal & 8:00-10:30 & & & & & sidente & R1-28 \\
\hline \multirow[b]{2}{*}{ Componente } & \multirow[b]{2}{*}{ Dependencia } & \multirow[b]{2}{*}{ № } & \multirow[b]{2}{*}{ Tarea } & \multicolumn{2}{|c|}{ Grúa } & \multirow{2}{*}{$\begin{array}{l}\text { Tiempo } \\
\text { (sg) }\end{array}$} & \multirow{2}{*}{$\begin{array}{l}\text { Factores } \\
\text { endógenos } \\
(\mathrm{A} / \mathrm{B} / \mathrm{C})\end{array}$} & \multirow{2}{*}{$\begin{array}{c}\text { Factores } \\
\text { exógenos } \\
(\mathrm{A} / \mathrm{B} / \mathrm{C})\end{array}$} & \multirow[b]{2}{*}{ Observaciones } \\
\hline & & & & Sí & No & & & & \\
\hline $\begin{array}{l}\text { Cambio pañal diurno } \\
\text { encamados }\end{array}$ & Moderado & 1 & $\begin{array}{l}\text { Comprobación } \\
\text { estado pañal }\end{array}$ & & & & & & \\
\hline Habitación $\cdots \rightarrow W C$ & Completo & 4 & Desplazamiento & & & & & & \\
\hline \multirow[t]{2}{*}{ Ducha o baño } & Completo & 5 & $\begin{array}{l}\text { Ducha/baño (aseo } \\
\text { personal) }\end{array}$ & & & & & & \\
\hline & & 6 & Secar e hidratar & & & & & & \\
\hline Pautas de pizarras & Indirecto & 7 & $\begin{array}{l}\text { Ejecutar pautas de } \\
\text { pizarras }\end{array}$ & & & & & & \\
\hline \multirow[t]{2}{*}{ Origen $\cdots>$ silla } & Grave & 2 & Transferencia & & & & & & \\
\hline & & 12 & Transferencia & & & & & & \\
\hline \multirow[t]{2}{*}{ Vestirse } & Completo & 3 & Desvestir & & & & & & \\
\hline & & 11 & Vestir & & & & & & \\
\hline Acicalamiento & Completo & 8 & Afeitado (hombre) & & & & & & \\
\hline Higiene bucal & Completo & 9 & Limpieza bucal & & & & & & \\
\hline Origen $\cdots$; habitación & Completo & 10 & Desplazamiento & & & & & & \\
\hline Origen $\rightarrow \rightarrow$ comedor & Completo & 13 & Desplazamiento & & & & & & \\
\hline Desayuno & Grave & 14 & Desayunar & & & & & & \\
\hline Origen $\cdots:$ actividades & Completo & 15 & Desplazamiento & & & & & & \\
\hline
\end{tabular}

A: alta incidencia. B: baja incidencia. C: incidencia considerable. Fuente: Elaboración propia.

Cada columna del registro debe contener la siguiente información:

- Componente: desglose de los distintos componentes implícitos en un determinado intervalo del día.

- Dependencia: valoración de la necesidad de ayuda de tercera persona, según clasificación de la CIF-OMS.

- №: código asociado a cada tarea descrita.

- Tarea: tareas que se han de realizar dentro de cada módulo (podrán identificarse fácilmente en las instrucciones de trabajo de las auxiliares de geriatría).

- Grúa: número de auxiliares necesarios para la ejecución de la tarea con ayuda técnica (uno o dos).

- Tiempo: tiempo computado en la ejecución del módulo/tarea, medido en segundos.

- Factores endógenos: alteraciones conductuales u otras cualesquiera que dilaten el proceso asistencial (incidencia alta, baja o considerable).

- Factores exógenos: efectos favorables o perjudiciales en el proceso asistencial, como por ejemplo, situaciones personales del colectivo auxiliar o conocimiento real del residente (incidencia alta, baja o considerable).

- Observaciones: campo libre para detallar al máximo cualquier información relevante que ayude a contextualizar el proceso asistencial y su medición.

\subsection{Tiempos indirectos}

Agrupados en tres módulos diferenciados ('mantenimiento de la salud', 'régimen hostelero' y 'tareas administrativas'), los tiempos indirectos se presentan en un total de trece componentes, repartidos a lo largo de la jornada laboral, de acuerdo a la organización interna de cada centro. Como ya hemos apuntado anteriormente, son tiempos asignables a tareas que no dependen de perfil alguno, a excepción de aquellas implícitas en el mantenimiento de la salud que interfieran directamente con el residente (administración de fármacos o estimulación física, por ejemplo), que no tienen por qué darse de igual manera en cada uno de los centros participantes en este estudio.

No todos los convenios o pactos de empresa recogen en idénticos términos las tareas y funciones de las auxiliares de geriatría o de enfermería. Si confrontáramos, por ejemplo, lo articulado por el Convenio Estatal y el extinto Convenio Colectivo de Gipuzkoa, nos encontraríamos con que dicen literalmente lo mismo:

- Según el plan funcional de las residencias, habrá de efectuar la limpieza y mantenimiento de los utensilios del residente, hacer las camas, recoger la ropa, llevarla a la lavandería y colaborar en el mantenimiento de las habitaciones.

- Limpia y prepara el mobiliario, materiales y aparatos de botiquín. 
- Colabora con el equipo de profesionales mediante la realización de tareas elementales que complementen los servicios especializados de aquéllos, en orden a proporcionar la autonomía personal del residente y su inserción en la vida social.

En consecuencia, tampoco disponemos de un marco común para describir un conjunto de tareas indirectas de aplicación generalizada. Análogamente a lo que sucede con la programación diaria de tareas directas, las indirectas también necesitan ser consensuadas. En algunos casos, el acuerdo sobre lo que debe contener la medición no supondrá problema alguno, puesto que son tareas implantadas en todos los geriátricos (hacer camas, recoger ropa, depositarla en contenedores de lavandería, limpiar efectos personales); en otros, sin embargo, la realidad puede ser tan variada que quizás requiera de la definición de un catálogo de tareas indirectas. El problema aún se complica más si dichas tareas estuvieran repartidas entre varias categorías profesionales (camareras, limpiadoras, lavanderas). En todo caso, cualquiera que fuera el escenario en cada centro, habría que definir un nuevo máximo común denominador y, sobre éste, estandarizar tiempos. Para algunas tareas, la medición sería diaria; esto es, cualquier día serviría de patrón o ejemplo (hacer camas o recoger ropa). Para otras, los datos se corresponderán con intervalos semanales, por cuanto que, si bien la tarea se realiza durante la semana, ni es diaria (colaborar con equipos profesionales, registros de calidad, reparto de pañales, colocación de ropa en armarios), ni tiene una cadencia concreta (registro y actuación sobre alteraciones conductuales, por ejemplo).

Las tareas indirectas no están tan influenciadas por factores exógenos o endógenos como las directas. Si bien es cierto que, para determinadas tareas del módulo 'mantenimiento de la salud', los factores exógenos podrían sesgar el tiempo, en general, se trata de trabajos muy concretos, de realización casi mecánica y que, bajo circunstancias normales, no deberían presentar dispersiones de consideración, salvo las correspondientes al saber hacer de cada uno de los centros. Aun así, se presume que la desviación entre centros no debe ser tal que nos haga pensar lo contrario. Por tanto, nuestro objetivo es determinar un valor agregado por residente y día que represente al sector. Con este ánimo, aprovecharemos el plazo previsto de mediciones (dos meses) para hacer acopio, también, de datos de atención indirecta conforme a los ítems definidos en el catálogo de tareas indirectas.

\section{Aplicación informática para la simulación de perfil-tiempo}

Hemos llegado a identificar qué vamos a medir (registro de toma de tiempos) y a qué personas ( $n$ y $n_{e}$ ). Pero, como ya se ha señalado, sería interesante ir analizando los datos para contrastar su validez y rigor. En cuanto se alcance un consenso respecto a lo que hemos denominado 'máximo común denominador' de tareas/funciones a un nivel concreto de apoyo de tercera persona, estaremos en disposición de diseñar la herramienta informática que soporte la estimación de tiempos para un perfil concreto. En cualquier caso, la herramienta debe ser sencilla en su manejo, intuitiva y permitir su ajuste a la realidad organizativa de cada centro. Con sólo activar o desactivar el ítem correspondiente, el resultado se verá modificado. Además, intentaremos combinar los distintos perfiles personalizados para extraer, en la medida de lo posible, grupos de consumo homogéneo, o isogrupos, con el ánimo de comparar cada centro con el sector. En la práctica, esta idea no es sino una lectura específica del case mix que debe ser entendida más como una valoración de ventajas (facilidades) o inconvenientes (dificultades) para la prestación del servicio que como un indicador de la financiación pública necesaria o, lo que es lo mismo, como un argumento para la modificación del coste/ plaza.

Si somos capaces de asignar tiempos estandarizados para un determinado nivel de confianza podremos construir un simulador de tiempos para distintos puntos de paso (apoyo de tercera persona correspondiente a cada nivel de dependencia) para cada ítem. Podremos, además, simular todas las combinaciones posibles para la escala elegida, de manera que, al menos teóricamente, podamos identificar isogrupos. Dada la cantidad de cálculos, procesos y alternativas presentes en el estudio, manejarse con una hoja de cálculo parece lo más aconsejable. En definitiva, se trata de operativizar un método que posibilite la identificación, asignación y clasificación de perfiles, en modo similar al que se propone para el BVD, eliminados los ítems no contemplables en geriátricos. La Figura 4 expresa, para valores ilustrativos no correspondientes a ninguna labor de campo, qué tiempo de auxiliar estaría asociado a cada nivel de dependencia para un perfil concreto. 


\begin{tabular}{|l|l|}
\hline Tiempos unitarios/día & 1 \\
\hline
\end{tabular}

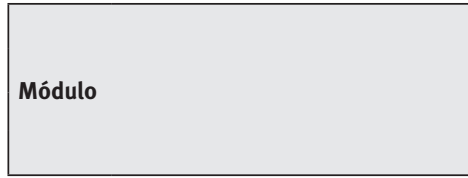

Tiempo de auxiliar (minutos/día)

\begin{tabular}{|c|l|}
\hline 1 & Comer \\
\hline 2 & Lavarse \\
\hline 3 & Vestirse \\
\hline 4 & Arreglarse \\
\hline 5 & Usar el retrete \\
\hline 6 & Trasladarse \\
\hline 7 & Deposición/micción \\
\hline 8 & Deambular/escalones \\
\hline 9 & Mantenimiento salud \\
\hline & Total directo \\
\hline
\end{tabular}

\begin{tabular}{|l|l|l|l|l|}
\hline \multicolumn{5}{|c|}{ Directo } \\
\hline Autónomo & Ligero & Moderado & Grave & Completo \\
\hline
\end{tabular}

\begin{tabular}{|c|l|}
\hline 10 & Mantenimiento salud \\
\hline 11 & Régimen hostelero \\
\hline 12 & Administrativas \\
\hline & Total indirecto \\
\hline
\end{tabular}

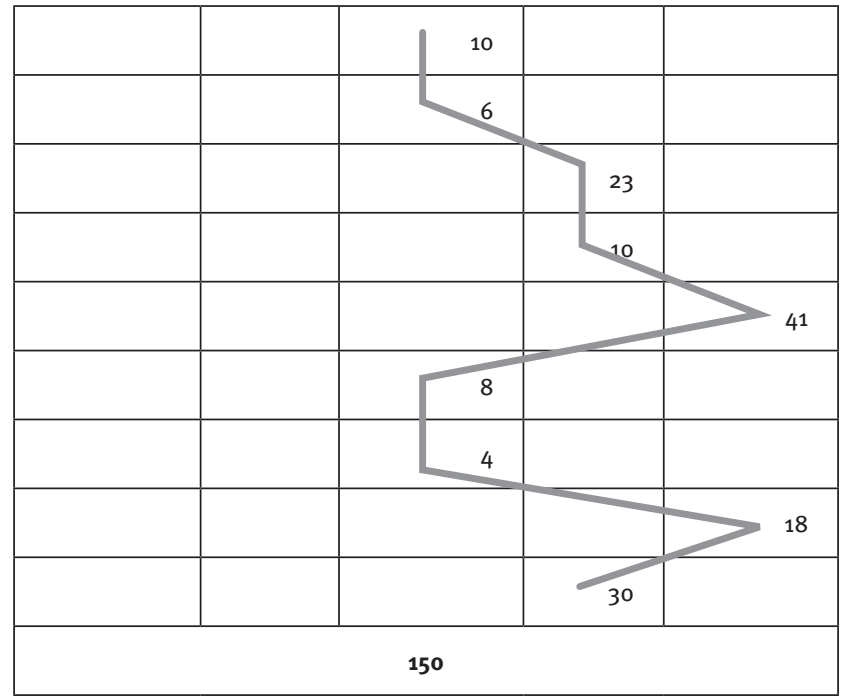

\begin{tabular}{|c|}
\hline Indirecto \\
\hline 12 \\
\hline 16 \\
\hline $\mathbf{8}$ \\
\hline 36 \\
\hline
\end{tabular}

Fuente: Elaboración propia.

\section{Supervisión como control de calidad}

Todo entramado teórico debe ser refrendado por la realidad en una dinámica propia de la sistemática PDCA (Plan-Do-Check-Act) [Planificar-Hacer-VerificarActuar]. Nuestro modelo no debería ser menos y, a partir de la observación y el análisis de los datos, deberíamos ser capaces de validar las estimaciones. tando las cifras por efecto de la propia experiencia adquirida.

Cualquiera que sea el método de contraste empleado, debe rotar sobre un eje inevitable: la supervisión del trabajo de atención directa. Ajustarse a los tiempos teóricos no asegura una buena pres- tación del servicio si éste no se supervisa. De igual modo que no podemos medir el tiempo de todas y cada una de las personas usuarias de un servicio residencial, tampoco podemos supervisar todas y cada una de las tareas/funciones descritas durante un día de atención y. mucho menos aún, garantizar que se hacen para la totalidad de la población. Nuevamente asoma la idea de trabajar con muestras estadísticamente significativas para componer el plano simétrico a la atención directa, que no es otro que el control de su calidad. La herramienta que estima tiempos deberá comprobar que éstos se ajustan y que además producen niveles de calidad dentro de los estándares definidos. De otra manera, nuestra reflexión no sería más que un puro ejercicio teórico sin aplicabilidad práctica. La capacidad 
para organizar, ordenar y traducir la realidad debe guiar nuestro rumbo; nuestro destino, sin embargo, debe ser la medición de tiempos y su contraste para validar el modelo.

Como personas que somos, factores de muy diversa índole nos condicionan diariamente y dificultan que los servicios asistenciales prestados en un geriátrico se sucedan conforme a una función de producción expresada en términos matemáticos, como de hecho ocurre en empresas de sectores como la energía o la automoción, en las que los factores productivos a corto plazo se mantienen constantes o sus variaciones obedecen a una escala previamente definida. En nuestro sector, la presencia de factores intangibles condiciona la producción de servicios al grado en que éstos se presenten, que, como ya hemos comentado, es aleatorio. La producción de ayuda de tercera persona en función del nivel de dependencia debe expresarse en términos de actos que un profesional debidamente formado ha de realizar para que un residente pueda tener cubiertas sus necesidades de la vida diaria (módulos del BVD-Barthel). Nuestro output es ayudar a una determinada intensidad dentro de una disponibilidad personalizada, siendo, además, eficientes. Dicho de otra manera, deberemos organizar el trabajo de la plantilla de auxiliares de tal modo que se conjuguen intensidades máximas (ayuda total o completa) y mínimas (supervisión) que garanticen una correcta y suficiente calidad en la prestación del servicio con el menor número posible de horas. En cierta medida, a pesar de las dificultades en definir una función de producción representa- tiva del sector o, en su defecto, de cada organización, se puede concluir que, al menos teóricamente, el escenario podría expresarse en el Gráfico 4.

La cuestión es definir lo que entenderemos como calidad estándar. Si analizáramos conjuntamente las ratios de todos y cada uno de los geriátricos de la CAPV, probablemente obtendríamos una línea de regresión para representar las distintas ratios observadas como la que describe el Gráfico 4. En cada caso, cada organización interpretará la prestación del servicio de manera particular y sin referenciar la calidad del servicio a ningún marco común. Surge, por tanto, la necesidad de diseñar una herramienta que permita estandarizar la calidad de dicho servicio de acuerdo a criterios objetivos y generales. Los resultados obtenidos en determinadas supervisiones clave nos aproximarán fielmente al nivel de calidad percibido como estándar. Pero no todos los módulos considerados para el BVD-Barthel tienen por qué ser parte del método de contraste de calidad. En concreto, los módulos relacionados con el aspecto saludable de los residentes deberían contener supervisiones específicas (higiene personal o control de esfínteres, por citar algunos), mientras que aquellos con contenido más 'mecánico' (desplazamientos o transferencias, por ejemplo) deberían integrar una supervisión más generalista. En cualquier caso, la implantación de un modelo de supervisión requiere que la organización tenga implementados determinados registros en un modelo de gestión de calidad. El Cuadro 7 recoge algunos de los ítems que se han de valorar en las distintas supervisiones.

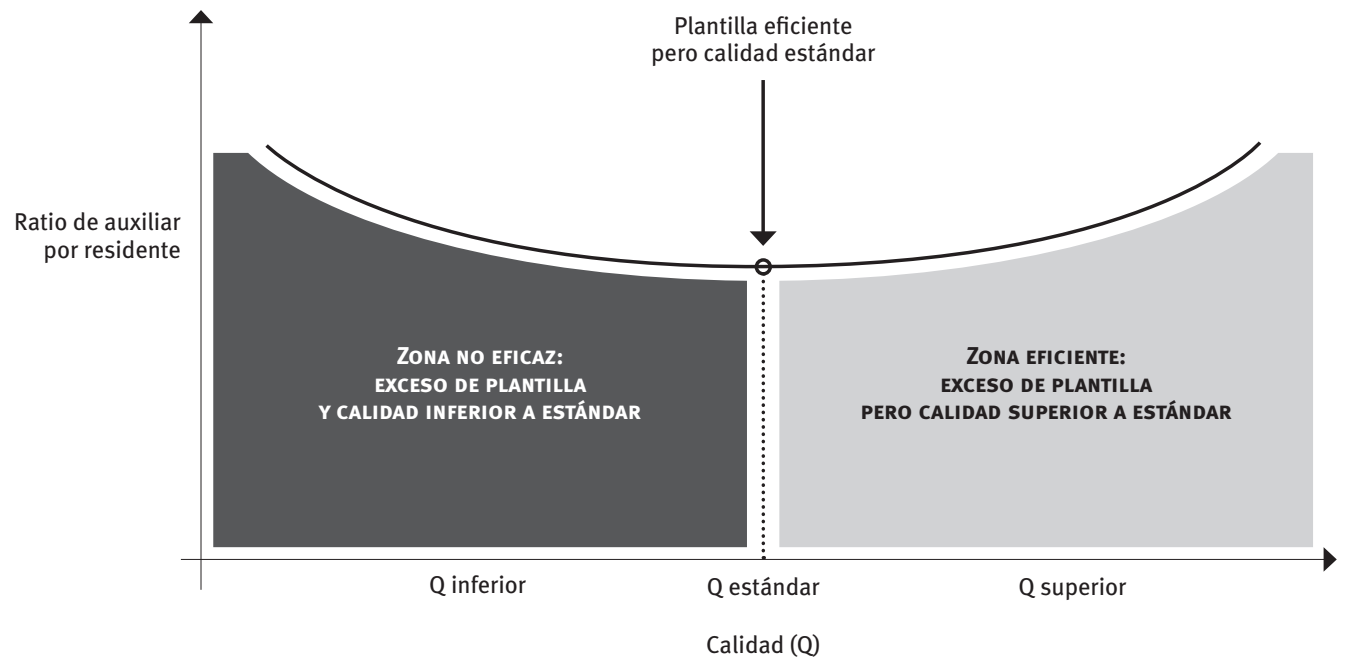

Fuente: Elaboración propia. 


\begin{tabular}{|c|c|c|}
\hline \multicolumn{3}{|c|}{ Cuadro 7. Indicadores para determinación de la calidad estándar } \\
\hline \multicolumn{3}{|c|}{ Supervisión mediante observación diaria y permanente } \\
\hline \multicolumn{3}{|c|}{$\begin{array}{l}\text { Se categorizará la mala praxis conforme a la siguiente escala, según su riesgo o consecuencia potencial: } \\
\text { grave }(g) \text {, moderado }(m) \text { y leve }(l)\end{array}$} \\
\hline Concepto & Detalle & Indicador \\
\hline Anotaciones & No anotar deposiciones u otras eliminaciones, o anotarlas mal. & \multirow{21}{*}{$\begin{array}{l}\qquad i_{1}=\frac{3 g+2 m+l}{c}\left(^{\star}\right), \\
\text { que, para que sea aceptado como } \\
\text { estándar, deberá cumplirse que } \\
i_{1} \leq i_{s t r} \text {. A su vez, el valor de este } \\
\text { parámetro podría calcularse como } \\
\text { sigue: } \\
i_{s t 1}=2 \cdot e_{r / d}{ }^{(*)}\end{array}$} \\
\hline Efectos de uso personal & No poner o quitar gafas, prótesis, dientes, bastones, etc. & \\
\hline Pañales & $\begin{array}{l}\text { Error en pañal colocado (confundido, mal adherido) o reponer mal } \\
\text { los pañales. }\end{array}$ & \\
\hline Restricciones y prevención & $\begin{array}{l}\text { No poner cinchas, cojines antiescaras, taloneras, almohada } \\
\text { postural, saco-cama, etc. }\end{array}$ & \\
\hline Tratamientos & No dar tratamientos pautados o darlos mal (medicación, pizarras). & \\
\hline Camas & Camas mal hechas, sucias, mojadas, etc. & \\
\hline Habitaciones & $\begin{array}{l}\text { Habitaciones mal recogidas (doble ropa, vasos sucios, sacar mal o } \\
\text { no sacar ropa). }\end{array}$ & \\
\hline Control esfínteres & No llevar a WC cuando hay necesidad. & \\
\hline Vestido & $\begin{array}{l}\text { Residentes mal vestidos, ropa combinada sin gusto, manchas, } \\
\text { suciedad, etc. }\end{array}$ & \\
\hline Levantar & No proceder a levantar al residente de la cama a tiempo. & \\
\hline Retraso en tareas & Terminar tarde tareas o no hacerlas. & \\
\hline Caso omiso a pautas escritas & $\begin{array}{l}\text { No leer parte de incidencias, tareas, registros, comunicaciones, } \\
\text { etc. }\end{array}$ & \\
\hline Aseo personal & Residentes mal aseados, acicalados, afeitados, lavados, etc. & \\
\hline Ubicación incorrecta & Olvidarse de algún residente en cualquier punto de la residencia. & \\
\hline Desplazamiento & Bajar tarde 0 a deshoras a los residentes. & \\
\hline WC & Dejar solos a los residentes en el WC. & \\
\hline Deambulación & Dejar que determinados residentes deambulen sin acompañante. & \\
\hline Medicación de mesilla & No reponer cremas, parches, pomadas, etc. & \\
\hline Alimentación & $\begin{array}{l}\text { No dar de comer, merendar o cenar, o preparar mal desayunos, } \\
\text { comidas o cenas. }\end{array}$ & \\
\hline Caídas & No registrar caídas. & \\
\hline Varios & Cajón de sastre para resto de errores detectados. & \\
\hline \multicolumn{3}{|l|}{ Supervisiones programadas } \\
\hline \multicolumn{3}{|c|}{ El indicador será el cociente entre las no conformidades observadas y el número de supervisiones realizadas) } \\
\hline Concepto & Detalle & Indicador \\
\hline Retrasos en aseo diario & $\begin{array}{l}\text { Registro de tiempo medio de retraso e identificación de causas } \\
\text { para cada grupo de baño/aseo. }\end{array}$ & \multirow{6}{*}{$i_{i} \leq 5 \%(\star \star \star)$} \\
\hline Supervisión de aseos diarios & $\begin{array}{l}\text { Detección de no conformidades en esta tarea, mediante } \\
\text { supervisión aleatoria. }\end{array}$ & \\
\hline Limpieza y orden de habitaciones & $\begin{array}{l}\text { Comprobación del orden y la limpieza en distintos elementos: } \\
\text { cajones, armarios, protectores, zapatos, útiles de aseo personal, } \\
\text { etc. }\end{array}$ & \\
\hline Limpieza de ayudas técnicas & $\begin{array}{l}\text { Supervisión del programa personalizado de limpieza y } \\
\text { mantenimiento del parque de sillas, andadores y de otras ayudas. }\end{array}$ & \\
\hline $\begin{array}{l}\text { Supervisión del programa de } \\
\text { acicalamiento personal }\end{array}$ & $\begin{array}{l}\text { Detección de no conformidades en el programa personalizado de } \\
\text { acicalamiento personal (depilación, manicura y pedicura). }\end{array}$ & \\
\hline Supervisión de limpieza bucal & $\begin{array}{l}\text { Detección de no realizaciones o errores en la limpieza diaria de } \\
\text { dientes y boca. }\end{array}$ & \\
\hline
\end{tabular}

* Evidentemente, la intensidad y la experiencia -traducida en conocimiento por quien supervisa- pueden producir diferencias entre organizaciones en cuanto al número de detecciones de malas praxis se refiere. El indicador resultante deberá combinar tanto el número de disconformidades como el porcentaje de cada riesgo potencial sobre el total. Si, además, consideramos que dicho indicador debe ser sensible al tamaño del geriátrico (cuanto mayor sea, mayor número de errores detectados), la expresión para calcular el valor del indicador podría ser la siguiente:

$$
i_{1}=\frac{e}{c} \cdot\left(\frac{3 g}{e}+\frac{2 m}{e}+\frac{l}{e}\right)=\frac{3 g+2 m+l}{c}
$$

\section{c: capacidad}

e: total de errores o malas praxis

$$
g \text { : errores graves (peso =3) } \begin{aligned}
& \text { m: errores moderados } \\
& (\text { peso }=2)
\end{aligned}
$$

l: errores leves

$($ peso $=1)$

** El valor del indicador estándar debe ser consecuencia de la observación empírica del número de errores cometidos en aquellos centros que tengan registrada esa información. Se expresará como producto de la constante 2 (valor medio de las diferentes combinaciones de $g, m$ y $/$ sobre el total de errores) y la constante $e_{r / d}$ o número medio de errores por residente y día, obtenido a partir de los datos aportados por organizaciones con este tipo de registro (según datos de una de las organizaciones, su valor medio se sitúa en trono a 0,05).

*** Dado que son supervisiones de tareas contempladas en respectivas instrucciones de trabajo, mediremos cuándo no se cumplen o se realizan erróneamente. Por defecto, cada profesional conoce sus competencias y responsabilidad y, por tanto, se permitirá una tasa máxima de error del $5 \%$. 


\section{Bibliografía}

(2011): "Real Decreto 174/2011, de 11 de febrero, por el que se aprueba el Baremo de Valoración de la Situación de Dependencia Establecido por la Ley 39/2006, de 14 de diciembre, de Promoción de la Autonomía Personal y Atención a las Personas en Situación de Dependencia”, Boletín Oficial del Estado, $\mathrm{n}$ - 42, 18-2-2011, págs. 18.567-18.691 [<https://www.boe.es/ buscar/doc.php?id=BOE-A-2011-3174'].

CALVO, F. (1990): Estadística aplicada, Ediciones Deusto.

ESPARZA, C. (2010): "Métodos de cálculo de la gravedad de la discapacidad", Informes Portal Mayores, no 103.

GÓMEZ ORDOKI, A. (2001): Sistema modular de costes y financiación en centros residenciales, Diputación Foral de Gipuzkoa.

GUADALAJARA, N. (1996): Análisis de costes en centros residenciales, serie Documentos Técnicos, Madrid, Imserso.

GUIJARO, J. L.; FONT M. T.; y ALZUGARAY, L. (1999): Estudio de carga asistencial de ancianos dependientes en residencias de Navarra, Pamplona.

IMSERSO (2005): "La valoración de la dependencia: criterios y técnicas de valoración y clasificación”, en IMSERSO, Atención a las personas en situación de dependencia en España. Libro blanco, Madrid, Imserso, págs. 553-631 [<http:// www.dependencia.imserso.es/InterPresent2/ groups/imserso/>].
IZAGUIRRE, A.; y CALVO AGUIRRE, J. J. (2014): “Índice de Barthel como detector precoz de cambios en el Baremo de Valoración de la Dependencia" [ponencia], XIII Congreso de Zahartzaroa y VII Congreso de la Sociedad Navarra de Geriatría y Gerontología, Bilbao, 8/10-5-2014.

KNAPP. M. (1988): La economía de los servicios sociales, Barcelona, Escola Universitària de Treball Social.

MINISTERIO DE TRABAJO Y ASUNTOS SOCIALES (2007): Manual de uso para el empleo del Baremo para la Valoración de la Dependencia (BVD), Madrid, Ministerio de Trabajo y Asuntos Sociales.

QUEREJETA, M. (2004): Discapacidad/dependencia: unificación de criterios de valoración y clasificación, Madrid, Imserso.

THOMPSON, J. R. et al. (2007): SIS. Escala de Intensidad de Apoyos [adaptación española de Verdugo, M. A.; Arias Martínez, B.; e Ibáñez García, A.], Madrid, TEA Ediciones.

VV.AA. (2013): Manual de uso para el empleo del Baremo para la Valoración de la Dependencia (con unificación de interpretaciones y criterios emitidos en CC. AA., realizada por el GT creado al efecto en el seno de la CTVGD y consensuada por ésta en su sesión plenaria del 18 de diciembre de 2013), Imserso. 